\title{
El modelo ecológico alternativo latinoamericano entre protección del derecho humano al medio ambiente y reconocimiento de los derechos de la naturaleza**
}

\section{The latin-american alternative ecological model between the protection of the environment as a human right and the recognition of the rights of nature}

SUMARIO

Introducción. I. De la reglamentación del aprovechamiento de los recursos naturales a la protección del derecho humano a un medio ambiente adecuado y sostenible. 1. La "demanialización" de los recursos naturales por parte del "constitucionalismo social" latinoamericano. 2. La "internacionalización" y "constitucionalización" del derecho a un medio ambiente adecuado para el desarrollo de la persona. II. De la protección del derecho humano al medio ambiente al reconocimiento de los derechos de la naturaleza. 1. La creación de un nuevo paradigma de protección ecológica: los derechos de la naturaleza. 2. Una alternativa al modelo capitalista de desarrollo: el ideal amerindio del "buen vivir"/"vivir bien". Conclusiones.

* Investigador del Istituto di Studi Giuridici Internazionali (ISGI) del Consiglio Nazionale delle Ricerche (CNR), con funciones en el Centro di Studi Giuridici Latinoamericani de la Università degli studi di Roma 'Tor Vergata' (CSGLA), Italia. Orcid iD: 0000-0002-0644-8397. Contacto: esborraz@juris.uniroma2.it

** Texto de la ponencia presentada a la reunión del Grupo de Trabajo de Jurisprudencia del Consejo Europeo de Investigaciones Sociales de América Latina (CEISAL), celebrada en ocasión del Segundo Foro Internacional "Rusia e Iberoamérica en el mundo globalizante: historia y perspectivas", organizado por la Universidad Estatal de San Petersburgo junto con el Instituto de Latinoamérica de la Academia de Ciencias de Rusia (San Petersburgo, 1-3/10/2015).

Recibido el 27 de octubre de 2015, aprobado el 16 de mayo de 2016.

Para citar el artículo: D. F. EsBorRAz, El modelo ecológico alternativo latinoamericano entre protección del derecho humano al medio ambiente y reconocimiento de los derechos de la naturaleza, Derecho del Estado n. ${ }^{\circ}$ 36, Universidad Externado de Colombia, enero-junio de 2016, pp. 93-129. Dor: http://dx.doi.org/10.18601/01229893.n36.04. 
RESUMEN

La preocupación del derecho latinoamericano por la "cuestión ambiental", que reconoce sus antecedentes en la "demanialización de los recursos naturales" por parte del "constitucionalismo social", cobra impulso a causa del desarrollo del "derecho ambiental internacional" y se intensifica con el advenimiento del denominado "nuevo constitucionalismo latinoamericano" y el desenvolvimiento de un verdadero "constitucionalismo ambiental" que reconoce ampliamente el derecho humano a un medio ambiente adecuado y sostenible. Esto, sin embargo, no ha logrado evitar del todo la depredación de la naturaleza, en atención a que ese derecho sigue respondiendo a una concepción marcadamente "antropocéntrica"; de ahí que el denominado "nuevo constitucionalismo andino", retomando la cosmovisión de los pueblos originarios de América Latina, ha propuesto reconocer directamente a la naturaleza el carácter de sujeto de derecho y completar este cambio de paradigma con la adopción de un modelo de desarrollo alternativo fundado en el principio ético-moral amerindio del "buen vivir"/"vivir bien".

\section{PALABRAS CLAVE}

Recursos naturales, derecho humano al medio ambiente, derecho al desarrollo, derecho ambiental internacional, constitucionalismo ambiental latinoamericano, derechos de la naturaleza, "buen vivir"/"vivir bien".

\section{ABSTRACT}

The concern of Latin-American Law about the "environmental issue" is rooted in the "inclusion of natural resources among the public goods" supported by the "Social Constitutionalism". Subsequently it has been revitalised thanks to the development of the "International Environmental Law" and further intensified with the rise of the "New Latin-American Constitutionalism" and the unfolding of a real "Environmental Constitutionalism" which is clearly recognising the human right to an adequate (for the development of the person) and sustainable environment. Nonetheless, in particular due to the fact that this law is built on a strongly "anthropocentric" conception, this was not enough to avoid nature despoil. Therefore, the so-called "New Andean Constitutionalism", by reaffirming the visio mundi of the Latin-American indigenous peoples, proposes to directly recognize the nature as a subject of law and to complete such a paradigm shift by adopting an alternative development model based on the Amerindian ethic-moral principle of the "Good Living"/"Living Well" ("Buen Vivir"/"Vivir Bien"). 
KEYWORDS

Natural Resources, Environment as a Human Right, Right to Development, International Environmental Law, Latin American Environmental Constitutionalism, Rights of Nature, "Good Living"/"Living Well” ("Buen Vivir"/"Vivir Bien").

\section{INTRODUCCIÓN}

La inconmensurable biodiversidad y la abundante disponibilidad de recursos naturales y energéticos con los que cuenta América Latina -sumados al carácter intercultural de la sociedad civil- constituyen sin lugar a dudas la principal riqueza de esta región, pero su aprovechamiento a lo largo de su historia no siempre se ha ajustado a criterios racionales ya que con frecuencia el mismo se ha visto condicionado por la implementación de modelos de desarrollo -puestos generalmente al servicio de las clases dominantes y/o de las grandes multinacionales- en desmedro no solo de la soberanía, la independencia y los intereses nacionales, sino también de la naturaleza y los derechos fundamentales de los sectores más vulnerables de la población (v.gr., los pueblos originarios).

Es por ello que no debe sorprendernos que, desde la aprobación -a inicios de los años setenta del siglo pasado- de los primeros instrumentos internacionales en materia medioambiental, los Estados latinoamericanos hayan abrazado rápidamente la "causa ecológica", dando inicio a un paulatino proceso de "institucionalización" de la gestión del medio ambiente y, en consecuencia, a un notorio incremento de la normativa ambiental (tanto sustantiva como adjetiva) en todos los niveles legislativos (llegándose incluso a su "constitucionalización"1), que por sus desarrollos reconoce muy pocos parangones en el ámbito del derecho comparado².

Lo mismo puede decirse en relación con los diversos mecanismos de integración regional o subregional en marcha en la región (v.gr., el Mercado

1 Por razones de extensión, en el presente trabajo nos limitaremos básicamente al análisis de la denominada "cláusula ambiental" contenida en los textos constitucionales de América Latina, lo que no significa que desconozcamos la rica legislación secundaria existente sobre esta materia en los diversos países latinoamericanos.

2 Ver en general, entre otros, Nonna, S. C. Derecho ambiental en América Latina. Buenos Aires, 1996; Benjamin, A. H. V.A. Proteção do meio ambiente nos países menos desenvolvidos: o caso da América Latina. Revista de Direito ambiental. Vol. 0, São Paulo, 1995, 92 ss.; BraÑES, $\mathrm{R}$. Informe sobre el desarrollo del derecho ambiental latinoamericano. Su aplicación después de diez años de la Conferencia de las Naciones Unidas sobre el Medio Ambiente y el Desarrollo. Programa de las Naciones Unidas para el Medio Ambiente (PNUMA). México, D. F., 2001; MEIER, H. El derecho ambiental y el nuevo milenio. Caracas, 2003, 16 ss., y CAFFERATA, N. A. Instituciones de derecho ambiental latinoamericano. Revista de Derecho Público. Vol. 2009-2 (Derecho ambiental). Santa Fe-Buenos Aires, 9 ss. 
Común Centroamericano-MCCA, la Comunidad Andina de Naciones-CAN, la Comunidad y Mercado Común del Caribe-CARICOM y el Mercado Común del Sur-MERCOSUR), en cuyo seno también se han ido generando normas de contenido ambiental, con amplias implicaciones para los países que los integran ${ }^{3}$. Particularmente emblemático en esta materia es el Tratado constitutivo de la Unión de Naciones Suramericanas (UNASUR), suscripto en Brasilia el 24 de mayo de 2008, cuyo artículo 2 reconoce expresamente como objetivo principal de esta nueva oganización internacional el de constituir “... un espacio de integración y unión en lo cultural, social, económico y político entre sus pueblos, otorgando prioridad al diálogo político, las políticas sociales, la educación, la energía, la infraestructura, el financiamiento y el medio ambiente, entre otros, con miras a eliminar la desigualdad socioeconómica, lograr la inclusión social y la participación ciudadana, fortalecer la democracia y reducir las asimetrías en el marco del fortalecimiento de la soberanía e independencia de los Estados"4.

El especial interés demostrado por el derecho de América Latina respecto a la denominada "cuestión ecológica" y las soluciones propuestas para hacer frente a la misma (algunas de las cuales -como se verá a continuación-se destacan por su originalidad) representan sin hesitación otro de los elementos de unidad y, a la vez, de resistencia del sistema jurídico latinoamericano, capaz de erigirse en esta materia en un modelo alternativo válido con virtualidad para proyectarse fuera de los confines de la región, en miras de la creación de un nuevo orden internacional. Esta otra particularidad del sistema jurídico latinoamericano, cuya base socio-cultural ha sido identificada en el denominado "bloque romano-indígena", en el cual el hombre no es tomado en consideración como un "individuo aislado" (tal como sucede en otras experiencias jurídicas, como la del common law) sino en estrecha relación con la "comunidad" y su "entorno", reconoce su fuente tanto en la tradición romanística (recibida, primero, a través del "derecho común ibero-americano" desarrollado durante el período colonial y, después, mediante su "transfusión" en las codificaciones que se dieron las repúblicas iberoamericanas luego de su Independencia), como también en el "mestizaje" de dicha tradición con las cosmovisiones de los pueblos originarios de Latinoamérica (las cuales fueron

3 Sobre este particular remitimos, entre otros, a REAL FERRER, G. ed., Integración económica y medio ambiente en América Latina. Madrid, 2000.

4 En honor a la verdad también los tratados constitutivos de la CAN (Cartagena, 1969) y del MERCOSUR (Asunción, 1991) hicieron referencia explícita a la necesidad de conservar el medio ambiente, aunque de manera menos contundente y muy probablemente como motivo de exigencias económicas; esto es, con el objeto de dar respuesta a las distorsiones de competitividad ocasionadas por las asimetrías normativas (ver, sobre este particular, MoREIRA, A. C. La protección ambiental en los procesos de integración. Aportes para cubrir un déficit del MERCOSUR. Anuario Mexicano de Derecho Internacional. Décimo Aniversario. México, D. F., 2012, 218 s., y 222). 
generalmente descuidadas por las codificaciones decimonónicas pero revalorizadas principalmente por el "nuevo constitucionalismo latinoamericano") 5 .

Partiendo de esta perspectiva, en el presente trabajo se analizan las principales característica del modelo ecológico latinoamericano, recorriendo las diversas etapas de su desenvolvimiento y los diferentes intentos llevados a cabo para garantizar de manera eficiente y eficaz la protección del medio ambiente (I), hasta llegar incluso a proponer el reconocimiento de la novedosa categoría de los derechos de la naturaleza (II).

\section{DE LA REGLAMENTACIÓN DEL APROVECHAMIENTO DE LOS RECURSOS} NATURALES A LA PROTECCIÓN DEL DERECHO HUMANO A UN MEDIO AMBIENTE ADECUADO Y SOSTENIBLE

\section{La "demanialización" de los recursos naturales por parte del "constitucionalismo social" latinoamericano}

El actual modelo ecológico latinoamericano reconoce sus antecedentes en la particular preocupación demostrada por el "constitucionalismo social" en reglamentar el aprovechamiento de los recursos naturales y energéticos (renovables o no) presentes en el suelo o en el subsuelo de la región ( $v . g r$., los bosques, los yacimientos de minerales, de piedras preciosas, de petróleo y carburos de hidrógeno sólidos, líquidos o gaseosos, las caídas de aguas y otras fuentes de energía hidráulica, las salinas y los ostrales de perlas), lo que es justificable si tenemos en cuenta que el desarrollo económico de América Latina ha estado ligado desde siempre a la explotación de su riqueza natural ${ }^{6}$.

Así, ya desde la sanción de la Constitución mexicana de Querétaro de 1917 -con la que se inauguró el "constitucionalismo social" en América Latina- las leyes fundamentales latinoamericanas se encargaron de precisar que pertenecen al dominio directo, inalienable e imprescriptible de la "Nación"”

$5 \quad \mathrm{Al}$ respecto ver, en general, Catalano, P. Diritto e persone. Torino, 1990, 114 ss.; Schipani, S. La codificazione del diritto romano comune. Torino, 1999, 180 ss.; Catalano, P. Choque de sistemas jurídicos en la perspectiva romana latinoamericanista. A propósito del "bloque romano-indígena": de Xalapa 1974 a Morelia 2006. En Cuevas Gayosso, J. L., comp., Estudios en homenaje a Mercedes Gayosso y Navarrete. Xalapa, 2009, 23 ss. y CAstellucCI, I. Sistema jurídico latinoamericano. Una verifica. Torino, 2011, 77 ss.; y, en relación con el tema que aquí nos ocupa, MARCELLI, F. La tutela dell'ambiente e la partecipazione democratica come elementi di una nuova identità latino-americana emergente. En CATALDI, G. y PAPA, A. coords., Ambiente, diritti e identità culturale. Napoli, 2006, 251 ss.

6 De ahí la preocupación demostrada ya por el Libertador Simón Bolívar (1783-1830) mediante las muchas medidas de gobierno adoptadas en materia de preservación de los recursos naturales (e, incluso, de los arqueológicos) en los territorios por él administrados luego de la Independencia de América Latina; sobre los cuales remitimos, de manera especial, a BolinAGA, M. B. Bolivar conservacionista. Caracas, 1982.

7 Ver, v.gr., CMéx/1917, art. 274; CArg/1949, art. 40²; CHon/1957, art. 6[3²], y CBol/1967, arts. 138 y 165 . 
o del "Estado" 8 los recursos de la naturaleza que se encuentren dentro de los límites de sus respectivos territorios ${ }^{9}$, procediendo de esa manera a su "demanialización". En efecto, el constituyente mexicano (rescatando los derechos que la Corona española se había asignado durante el período colonial) ${ }^{10}$ declaró que "[1]a propiedad de la tierra y de las aguas comprendidas dentro de los límites del territorio, corresponden originariamente a la Nación, la cual, ha tenido y tiene el derecho de transmitir el dominio de ellas a los particulares, constituyendo la propiedad privada" (art. 27, primer párrafo), y en consecuencia precisó, además, que "[1]a Nación tendrá en todo tiempo el derecho de imponer a la propiedad privada las modalidades que dicte el interés público, así como el de regular el aprovechamiento de los elementos naturales suceptibles de apropiación, para hacer una distribución equitativa de la riqueza pública..." (art. 27, tercer párrafo).

De los textos transcritos se desprende que para la Constitución mexicana de 1917 la propiedad privada dejaba de ser considerada un derecho natural del propietario (como presuponía el denominado "constitucionalismo liberalconservador" imperante en América Latina desde mediados del siglo XIX) para pasar a concebírsela como un derecho derivado del dominio originario o del imperio que la Nación tiene sobre su territorio (comprensivo del suelo, del subsuelo y del mar territorial); reconociéndosele además a la misma -como corolario- una "función social" predominante, al tratar de armonizar las garantías individuales del propietario con las garantías sociales, y de coordinarlas con los recíprocos deberes que su ejercicio impone, tal como luego hicieran también la casi totalidad de los textos constitucionales de América Latina ${ }^{11}$.

Ahora bien, respecto a la incorporación de los recursos naturales al dominio público (es decir, dentro de la categoría de las res publicae) cabe destacar que ella persiguió la finalidad concreta y deliberada de garantizar la gestión y utilización controlada o equilibrada de los mismos (en orden a su preservación), otorgando a los poderes públicos las máximas facultades para evitar que la intensidad o lesividad de la actividad privada conduzca a su menoscabo o deterioro; aun cuando de todos modos se admitiera -en algunos casos y bajo las condiciones previstas por la legislación correspondiente- la

8 Ver, v.gr., la CPer/1933, art. 37; CBra/1934, art. 118; CBra/1937, art. 143; CCub/1940, art. 88; CBra/1946, art. 152; CSal/1950, art. 137³; CBra/1967, art. 161; CEcu/1967, art. 55², y CPar/1967, art. 100.

9 Sobre el particular ver, entre otros, RÁBAGO DORBECKER, M. Derechos de propiedad: artículo 27 constitucional y artículo 21 convencional. En Ferrer MAC-Gregor PoIsot, E.; CABAllero Ochoa, J. L. y Steiner, Chr. coords., Derechos humanos en la Constitución. Comentarios de jurisprudencia constitucional e interamericana. Vol. II. México, D. F., 2013, 2299 ss.

10 Ver, en este sentido, González, M. del R. Del Señorío del Rey a la propiedad originaria de la Nación. Anuario Mexicano de Historia del Derecho. Vol. 5. México, D. F., 1993, 129 ss.

11 Ver, v.gr., los arts. $34 \mathrm{CPer} / 1933,113[17] \mathrm{CBra} / 1934,30^{2} \mathrm{CCol} / 1886-1936,87$ CCub/1940, 147 CBra/1946, 183 CEcu/1946, 17 CBol/1947, 38 CArg/1949, 137 CSal/1950, 157 CHon/1957, 7[9] CBol/1967, 150[22] y 157[III] CBra/1967, y 96 CPar/1967. 
posibilidad de dar en concesión su explotación a los particulares (sean estos nacionales o personas jurídicas extranjeras radicadas en el país $)^{12}$. Sobre este particular algunas constituciones latinoamericanas precisaron además que la "exploración", "explotación" o "utilización" de los recursos naturales y energéticos debía hacerse en forma "regular" o "racional", precautelando así su "defensa", "fomento", "conservación", "renovación" y/o "incremento"13.

Sin embargo, cabe señalar que en esta "primera oleada" del reformismo constitucional latinoamericano ${ }^{14}$, la protección de la naturaleza se encuentra aún motivada casi exclusivamente en criterios económicos, en cuanto los límites impuestos a la explotación de sus recursos tenía como principal finalidad la de lograr un mejor aprovechamiento de los mismos en miras a garantizar el desarrollo económico del país (con la finalidad de hacer una distribución equitativa de la riqueza y cuidar su conservación), pero sin condicionarlo al respeto del medio ambiente ${ }^{15}$. Ello respondía al "mito" (promovido incluso durante décadas por instituciones financieras internacionales como el Fondo Monetario Internacional y el Banco Mundial) según el cual el crecimiento económico es igual a la prosperidad y al mayor respeto de los derechos humanos; idea esta que con el tiempo se ha demostrado falaz, pues como se sabe

12 Ver, v.gr.,CMéx/1917, art. 27[I]; CPer/1933, art. 37; CSal/1950, art. 13733; CHon/1957, art. 6[3'] ; CBol/1967, art. 139i.f.; CEcu/1967, art. 55, y CPar/1967, art. 101. Una situación particular en esta materia está representada por las constituciones históricas brasileñas, las que si bien admitían que los recursos naturales pudiesen ser de propiedad de los particulares, exigían para su explotación una autorización del Estado (ver CBra/1934, art. 119; CBra/1937, art. 143[pr.]; CBra/1946, arts. 152 y 153, y CBra/1967, art. 161[1]). Por último, cabe recordar que algunas cartas constitucionales latinoamericanas se habían preocupado, además, por establecer expresamente el monopolio estatal para la exploración, explotación y producción de ciertos recursos extratégicos como el petróleo (v.gr., CMéx/1917-1939, art. 27 $7^{6 i f}$ y CBra/1967, art. 162) o para su exportación (v.gr., CBol/1947, art. 110²).

13 Ver, v.gr., CMéx/1917, art. 276; CHon/1957, art. 254; CVen/1961, arts. 106 y 136[10]; CEcu/1967, arts. $51^{2}$ y $55^{2}$, y CPar/1967, arts. 94 y 132. Estas disposiciones, algunas de las cuales reconocerían sus antecedentes también en la "Conferencia de las Naciones Unidas sobre conservación y utilización de los recursos" (New York, 17/8-6/9/1949), constituyen el germen del principio del "desarrollo sostenible" que con el tiempo será profundizado -en un primer momento- por el derecho ambiental internacional y -a partir de los años ochenta del siglo xxpor el derecho constitucional latinoamericano.

14 Emplean esta expresión para referirse al "constitucionalismo social" latinoamericano Gargarella, R. y Courtis, Chr. El nuevo constitucionalismo latinoamericano: promesas e interrogantes. CEPAL - Serie Políticas Sociales. Vol. 153. Santiago de Chile, 2009, 25.

15 Por ello no es casual que las disposiciones constitucionales que se ocupaban del modo como debían ser aprovechados los recursos naturales integrasen la denominada "Constitución económica", es decir, el mismo plexo normativo (o, incluso, la misma norma) que se encargaba de regular el "orden" o "régimen económico" de la Nación (tal como se desprende, v.gr., de los arts. 115,118 y $119 \mathrm{CBra} / 1934 ; 143 \mathrm{CBra} / 1937 ; 152$ y $153 \mathrm{CBra} / 1946 ; 40^{1-2} \mathrm{CArg} / 1949 ; 95$ y 106 CVen/1961; 133 CBol/1967; 157 [pr.], 161 y 162 CBra/1967; 94 CPar/1967, y 32² CCol/18861968). Emblemático al respecto resultaba el artículo 56 CEcu/1967, el cual expresamente disponía que "[e]l aprovechamiento de los recursos naturales, cualesquiera sean sus dueños, se regulará de acuerdo con las necesidades de la economía nacional". 
este tipo de crecimiento beneficia solo los intereses privados de una ínfima minoría y es fuente de graves violaciones de los derechos fundamentales de la mayor parte de la poblicación (ver infra II.2).

No obstante ello, ya antes del desarrollo del denominado "constitucionalismo ambiental latinoamericano" (ver supra I.2) ${ }^{16}$ algunas de las cartas constitucionales de América Latina habían puesto también la atención en la protección de "las bellezas naturales" (Constitución costarricense de 1949, art. 89) o de "as paisagens naturais notáveis" (Constitución brasileña de 1967, art. 172), introduciendo de esta manera un criterio axiológico de tutela del medio ambiente basado no en su utilidad económica sino en su capacidad de causar asombro o deleite (dada su extraordinaria belleza), aun cuando el fundamento seguía siendo "antropocéntico" pues los elementos de la naturaleza solo eran considerados dignos de protección por su aptitud para satisfacer el placer humano y no por su valor intrínseco ${ }^{17}$. La fuente de estas disposiciones podría encontrarse en la "Convención para la preservación de la flora, de la fauna y de las bellezas escénicas naturales de los países de América" (Washington, 12/10/1940), adoptada en el seno de la entonces Unión Paramericana y aprobada luego por la mayoría de los Estados americanos, con el objetivo de proteger y conservar en su medio ambiente natural ejemplares de todas las especies y géneros de su flora y de su fauna indígena, así como también los paisajes de incomparable belleza, las formaciones geológicas extraordinarias y los objetos naturales de interés y valor histórico o científico ${ }^{18}$.

\section{La "internacionalización" y "constitucionalización” del derecho a un medio ambiente adecuado para el desarrollo de la persona}

El interés del derecho latinoamericano por la "cuestión ecológica" cobra impulso como consecuencia del desarrollo del "derecho ambiental internacional" 19

16 Denominación acuñada por el jurista mexicano BrAÑEs, R. El constitucionalismo ambiental latinoamericano. En Cordini, G. y Postiglione, A., eds., Ambiente e cultura. Patrimonio comune dell'Umanità. Atti della VII Conferenza Internazionale ICEF (Paestum, 6-10 giugno 1997). Napoli, 1999, 129 ss.

17 Como ha destacado IzaguirRe SARKís, C. Introducción al derecho ambiental. En AguILAR, G. y IzA, A., eds. y dirs. Manual de Derecho ambiental en Centroamérica. San José de Costa Rica, 2005, 23, y 26 s.

18 En honor a la verdad, ya la Constitución de la segunda República Española de 1931 había dispuesto en su artículo $45^{2}$ que el Estado protegía también "los lugares notables por su belleza natural o por su reconocido valor artístico o histórico" (acerca de la influencia de la CEsp/1931 sobre las constituciones de América Latina ver, en general, Pérez Royo, J. Influencia del constitucionalismo español en el constitucionalismo iberoamericano. En CARBonELL, M.; CARpizo, J. y Zovatto,D., coords., Tendencias del constitucionalismo en Iberoamérica. México, D. F., 2009, 421).

19 El cual está estrechamente vinculado al derecho internacional de los derechos humanos (ver, en general, CANÇAdo Trindade, A. A. Direitos humanos e meio-ambiente. Paralelo dos sistemas de proteção internacional. Porto Alegre, 1993 y Oliveira Mazzuoli, V. DE. A proteção 
partir de finales de los años sesenta y principios de los setenta del siglo xx, particularmente con motivo de la Conferencia de las Naciones Unidas sobre el Medio Humano (Estocolmo, 5-16 de junio de 1972), la cual constituyó la primera gran cumbre de la historia dedicada a la problemática medioambiental y que culminó con una declaración de principios (aprobada por la Asamblea General de ONU por medio de la Resolución 2994 del 15 de diciembre de 1972) que iniciaba afirmando que "[e]l hombre tiene el derecho fundamental a [...] el disfrute de condiciones de vida adecuadas en un medio ambiente de calidad tal que le permita llevar una vida digna y gozar de bienestar..." (principio 1 , primera parte ${ }^{20}$.

La denominada "Declaración de Estocolmo" contuvo 26 principios en los que -entre otras cosas- se estableció: i) la vinculación de la protección del derecho fundamental a un medio ambiente de calidad con los derechos humanos a una vida digna, a la libertad y a la igualdad (principio 1); ii) los lineamientos para la salvaguarda de los recursos naturales y de los ecosistemas en beneficio de las generaciones presentes y futuras (principios 2, 3 y 5); iii) el deber de poner fin a las descargas de sustancias tóxicas que puedan poner en peligro la salud del hombre o causar daños graves e irreparables a los ecosistemas (principios 6 y 7); iv) el vínculo existente entre el desarrollo económico y social y la protección del medio ambiente, pero teniendo en cuenta las particularidades de los países en vías de desarrollo (principios 8 a 16 y 23); v) la conveniencia de aplicar algunos instrumentos, tales como la planificación ambiental (lo cual incluye herramientas como los planes de acción), de modo que quede asegurada la compatibilidad del desarrollo con la necesidad de proteger y mejorar el medio ambiente (principios 13 a 15); vi) la recomendación de crear autoridades nacionales con competencia para planificar, controlar y administrar los recursos ambientales (principio 17), iniciando así el camino hacia una gestión ambiental mucho más coherente; vii) la necesidad de fomentar la investigación y el desarrollo científico (principios 18 y 20), la educación ambiental (principio 19) y la cooperación internacional (principios 22, 24 y 25).

internacional dos Direitos Humanos e o Direito Internacional do medio ambiente. Revista de Direito ambiental. Vol. 34. São Paulo, 2004, 97 ss.).

20 Entre los antecedentes más destacados de la Convención de Estocolmo pueden citarse la "Conferencia Intergubernamental de Expertos de la UNESCO sobre las bases científicas de la utilización racional y la conservación de la biosfera" (París, 4-13 de setiembre de 1968) y la "Convención de las Naciones Unidas relativa a los humedales de importancia internacional, especialmente como hábitat de aves acuáticas" (RAMSAR, 2 de febrero de 1971). También cabe señalar, por estos mismos años, los trabajos del denominado "Club de Roma" fundado en 1969 por un grupo de intelectuales y científicos para reflexionar sobre el impacto ambiental y social del crecimiento económico y del estilo de vida occidental, el cual en 1972 elaboró su primer informe intitulado "Los límites del crecimiento" (ver Meadows, D. H.; Randers, J. y Behrens III., W. W. The Limits to Growth. New York, 1972). 
Correspondió a la Constitución panameña que entró en vigor el 11 de octubre de 1972 el mérito de haber "constitucionalizado" por primera vez la materia medioambiental ${ }^{21}$ al disponer en su artículo 110 que "[e]s deber fundamental del Estado velar por la conservación de las condiciones ecológicas, previniendo la contaminación del ambiente y el desequilibrio de los ecosistemas, en armonía con el desarrollo económico y social del país" (texto original) ${ }^{22}$. En esta primera regulación de la materia por parte de un texto constitucional se impuso al Estado -además- el deber de asegurar la compatibilidad del desarrollo con la necesidad de proteger y mejorar el medio ambiente en beneficio de la población, tal como había recomendado la referida "Declaración de Estocolmo" (principio 13).

Este ejemplo fue seguido poco tiempo después por la Constitución cubana de 1976, la cual impuso el deber de salvaguardar el entorno natural no solo a los poderes públicos sino también a la "sociedad", al disponer en su artículo 27 que "[p]ara asegurar el bienestar de los ciudadanos el Estado y la sociedad protegen la naturaleza. Incumbe a los órganos competentes y además a cada ciudadano, velar porque sean mantenidas limpias las aguas y la artmósfera, y que se proteja el suelo, la flora y la fauna" (texto original) ${ }^{23}$; esto en consonancia con lo establecido también por la "Declaración de Estocolmo", la cual, inmediatamente después de haber reconocido el derecho humano a disfrutar de un medio ambiente de calidad, agregó que "[el hombre] tiene la solemne obligación de proteger y mejorar el medio ambiente para las generaciones presentes y futuras" (principio 1, segunda parte) ${ }^{24}$.

Este proceso de "enverdecimiento constitucional" 25 se intensificó con el advenimiento del denominado "nuevo constitucionalismo latinoamericano", desarrollado a partir de los años ochenta del siglo $\mathrm{xx}^{26}$ con motivo de la caída

21 En Europa, la primera Constitución que reguló expresamente este derecho fue la griega de 1975 (art. 24.1), seguida por la portuguesa de 1976 (art. 66), la española de 1978 (art. 45) y más tarde, entre otras, por la de la Federación Rusa de 1993 (art. 42) y por la reforma introducida en 1994 a la Constitución alemana de 1949 (art. 20a).

22 La CPan/1972 fue reformada por el Acto constitucional de 1983, que desarrolló aún más la normativa ambiental a través de la incorporación de un Capítulo vII $a d$ hoc intitulado "Régimen ecológico" (arts. 114-117, que luego de la reforma de 2004 devinieron los actuales arts. 118-121).

23 En efecto, fiel a la ideología del socialismo marxista, la CCub/1976 no reconoció derechos subjetivos en esta materia sino el deber de "cada ciudadano" de "velar porque sean mantenidas limpias las aguas y la atmósfera, y que se proteja el suelo, la flora y la fauna" (ver, en este sentido, MeIER, H. El derecho ambiental y el nuevo milenio, cit., p. 19).

24 Aun cuando el tex to original del artículo 27 CCub/1976 no hacía referencia a la "sustentabilidad", la que recién fue introducida con la reforma de 1992 por influencia de la Declaración de Río sobre el medio ambiente y el desarrollo del mismo año (ver infra en el texto).

25 Denominación empleada por CAFFERATA. Instituciones de Derecho ambiental latinoamericano, cit., p. 9.

26 Sin embargo, consideramos que la primera Constitución de este grupo fue la de Perú de 1979 , la cual dispuso que los preceptos contenidos en los tratados relativos a los derechos 
de las dictaduras cívico-militares que asolaron la mayor parte de los países de América Latina en la década precedente, cuyas características más sobresalientes -en lo que aquí interesa-son: i) el cambio de la identidad axiológica de las constituciones de la región, cuyos textos fueron reformados en su gran mayoría, ya sea sustituyéndolos in toto ${ }^{27} \mathrm{o}$ modificándolos solo de manera parcial pero mudando su sustancia ${ }^{28}$; ii) una especial consideración de la teoría de los derechos humanos que se tradujo en el abundante catálogo de derechos reconocidos y garantizados por las constituciones latinoamericanas, no solo individuales (de las personas en particular) sino también colectivos o difusos (de las comunidades, pueblos, nacionalidades o grupos) e incluso, últimamente, a favor de la naturaleza (ver infra ii.1) 29; $^{29}$ iii) la adopción de mecanismos de participación ciudadana complementarios de las instituciones propias de la democracia representativa (como el Defensor del Pueblo o el referéndum, el plebiscito, la iniciativa popular, la revocación del mandato, la consulta previa, etc.); vi) la preocupación por lograr la máxima efectividad de los derechos reconocidos, completando sus regulaciones con la introducción de instrumentos de protección jurídica reforzada de los mismos (como el amparo, el habeas corpus, el habeas data, las acciones populares y de grupo, etc.), y v) la conversión del "Estado 'legislativo' de derecho" (o "Estado legal") en un "Estado 'constitucional' de derecho" (o "Estado constitucional"), concibiendo la Constitución como un mandato directo del poder constituyente al poder constituido (o poder legal) cuya resultante es la "constitucionalización" del ordenamiento jurídico (la que opera tanto en el plano interpretativo como aplicativo de todo el ordenamiento jurídico).

humanos tenían jerarquía constitucional y que no podían ser modificados sino por el procedimiento que regía la reforma de la Constitución (art. 105). Asimismo, en lo que respecta estrictamente a la tutela del medio ambiente, esta Constitución tuvo también el mérito de haber reconocido en forma nítida, por primera vez, el derecho humano fundamental a habitar en un medio ambiente adecuado (art. 123); ya que -como acabamos de ver en el texto- la CPan/1972 y la CCub/1976, que la precedieran en el tiempo, lo habían concebido -respectivamente- solo como un "deber" del Estado o de este y de la sociedad (ver infra nota 39).

27 V.gr., CPer/1979, CEcu/1979, CHon/1982, CSal/1983, CGua/1985, CNic/1986, CBra/1988, CCol/1991, CPar/1992, CEcu/1998, CVen/1999. Incluso, en ciertos casos, se ha producido ya la sustitución de algunos de estos textos constitucionales (tal como ha sucedido con la CPer/1979, reemplazada por la CPer/1993, y la CEcu/1979, sustituida por la CEcu/1998, y esta, a su vez, por la CEcu/2008).

28 V.gr., CCh/1981-1989, CCR/1949-1989, CMéx/1917-1992-2011 y CArg/1853-1994.

29 Este catálogo se ve ampliado, además, por el reenvío que la mayor parte de las constituciones latinoamericanas vigentes hacen a los textos de los instrumentos internacionales sobre derecho fundamentales y por la consecuente aplicación de los principios de progresividad (ver, v.gr., CVen/1999, art. 19; CEcu/2008, art. 423.3, y CMéx/1917-2011, art. 1[3]) y de interpretación pro homine (ver, v.gr., CEcu/1998, art. 18[2]; CEcu/2008, arts. 11.5 y 427, y -más claramenteCMéx/1917-2011, art. 1[2]), el que incluso en algunas constituciones de la región devino pro homine et natura (v.gr., CEcu/2008 y CBol/2009 [ver infra II.1]). 
Ahora bien, por lo que respecta estrictamente al derecho ambiental, la mayor parte de las leyes fundamentales pertenecientes a esta "segunda oleada" 30 del reformismo constitucional latinoamericano ${ }^{31}$ se ha preocupado también por reglar de manera especial el aprovechamiento de los recursos naturales y de destacar su relación estrecha con el desarrollo económico continuando de esta manera con la tendencia inaugurada en esta materia por el "constitucionalismo social" (ver supra I.1)-, pero condicionando ahora ambos aspectos a la protección del medio ambiente y, consecuentemente, a la "sustentabilidad" o "sostenibilidad" 32 ; tal como postulara la Conferencia de las Naciones Unidas sobre el Medio Ambiente y el Desarrollo (Río de Janeiro, 3-14 de junio de 1992) 33 $^{33}$ la que concluyó también con una declaración de principios que inicia proclamando que "[1]os seres humanos constituyen el centro de las preocupaciones relacionadas con el desarrollo sustentable" y que "[t]ienen derecho a una vida saludable y productiva en armonía con la naturaleza" (principio 1) ${ }^{34}$.

La denominada "Declaración de Río" (aprobada por la Asamblea General de las Naciones Unidas por medio de la Resolución 47/190 del 22 de diciembre de 1992) contuvo 27 principios (algunos de los cuales, como es fácil de advertir, reiteraron los de la Declaración de Estocolmo) entre los que pueden destacarse: i) la prevención de los daños ambientales (principio

30 Ver, asimismo, sobre esta otra expresión GARGARELLA y CouRTIS. El nuevo constitucionalismo latinoamericano, cit., p. 25.

31 Algunas de las cuales (como hemos visto supra nota 27) fueron ya sustituidas en su totalidad pero manteniendo o, incluso, actualizando las disposiciones medioambientales, mientras que otras han solo reformado parcialmente su normativa para introducir la regulación de la materia ambiental (v.gr., CEcu/1979-1983, CCR/1949-1994 y CUru/1967-1996) o para profundizar la regulación ya existente (v.gr., CPan/1972-1983, CCub/1976-1992 y CUru/1967-1996-2004). Una consideración especial merecen la CEcu/2008 y la CBol/2009, las que como veremos a continuación no solo se han limitado a actualizar las respectivas "cláusulas ambientales" sino que incluso han introducido un nuevo "paradigma ecológico" (ver infra II).

32 Así -v.gr.- lo han dispuesto, expresa o implícitamente, la CPan/1972-1983-2004, art. 121; la CGua/1985, art. 97; la CBra/1988, arts. 170[vi] y 186[II]; la CCol/1991, art. 801; la CCub/1976-1992, art. 27; la CPar/1992, art. 7; la CPer/1993, art. 67; la CArg/1853-1994, art. 41' CCR/1949-1994, art. 50; la CEcu/1998, arts. 86[2] y 243[1]; la CMéx/1917-1999, art. 25; la CVen/1999, art. 299; la CSal/1983-2000, art. 117'; la CUru/1967-1996-2004, art. 473[1.b]; la CEcu/2008, art. 14; la CBol/2009, art. 306.III, y la CRD/2010, art. 17.

33 Entre los antecedentes de la Convención de Río, que también han servido de fuente directa al derecho ambiental latinoamericano, se destacan la Resolución 37-7 del 28 de octubre de 1982 (llamada "Carta Mundial de la Naturaleza"), la "Declaración sobre el Derecho al Desarrollo" adoptada por la Asamblea General de las Naciones Unidas en su Resolución 41/128 del 4 de diciembre de 1986 y, principalmente, el documento intitulado "El nuevo futuro común", elaborado en 1987 por encargo de las Naciones Unidas por la Comisión Mundial sobre el Medio Ambiente y el Desarrollo presidida por la que fue Primera Ministra de Noruega, Gro Harlem Brundtland (conocido como "Informe Brundtland").

34 Sin embargo, es digno de señalar que -tal como veremos a continuación- algunas constituciones latinoamericanas ya se habían anticipado a muchas de las recomendaciones de la Cumbre de Río de 1992 (así CBra/1988, CCol/1991 e, incluso, la contemporánea CPar/1992). 
2); ii) la equidad inter e intrageneracional (principio 3); iii) la integración de la variable ambiental en el proceso de desarrollo (principio 4); iv) la erradicación de la pobreza como requisito indispensable del desarrollo sostenible (principio 5); v) las responsabilidades comunes pero diferenciadas de los Estados, en vista de que han contribuido de distinta manera a la degradación del medio ambiente mundial (principio 7); vi) la reducción y eliminación de modalidades de producción y de consumo insostenibles (principio 8); vii) la cooperación para la investigación y la transferencia de tecnología (principio 9); viii) la participación y el acceso a la información ambiental de todos los ciudadados interesados, en el nivel que corresponda (principio 10); ix) la necesidad de una legislación eficaz para la protección del medio ambiente (principio 11) y, en particular, con relación a la responsabilidad e indemnización del daño ambiental (principio 13); xi) la cooperación para desalentar o evitar la reubicación y la transferencia a otros Estados de actividades y sustancias que causen degrado ambiental o sean nocivas para la salud (principio 14); xii) la aplicación del criterio de precaución (principio 15) y de que "quien contamina paga" (principio 16); xiii) la importancia de las evaluaciones de impacto ambiental (principio 17); xiv) la notificación e intercambio de información sobre desastres naturales o actividades que afecten el medio ambiente de otros Estados (principio 18) y la celebración de consultas por actividades que puedan tener efectos transfronterizos (principio 19); xv) el papel fundamental que están llamados a cumplir, en la ordenación del medio ambiente y en el desarrollo, las mujeres y los jóvenes (principios 20 y 21), así como también las poblaciones indígenas y otras comunidades locales (principio 22); xvi) la condena a la guerra como enemiga del desarrollo sostenible y el vínculo entre la paz, el desarrollo y la protección del ambiente (principios 24,25 y 26 ); etc. ${ }^{35}$.

De esta manera, en cumplimiento de los compromisos internacionales asumidos por los países latinomaricanos en las conferencias de Estocolmo (1972) y Río de Janeiro (1992) ${ }^{36}$, la casi totalidad de los textos constitucionales de la región fueron reconociendo paulatinamente el derecho humano fundamental a gozar o disfrutar de un medio ambiente adecuado (es decir, sano y ecológicamente equilibrado ${ }^{37}$ para el bienestar y el desarrollo de la

35 Además de la referida Declaración de Principios, la Conferencia de Río aprobó un plan de acción titulado "Programa 21" (o "Agenda 21") y una "Declaración sobre Bosques", así como también en ella se dio inicio a la suscripción de dos importantes acuerdos internacionales de alcance mundial: i) la "Convención marco sobre el cambio climático" y ii) el "Convenio sobre la diversidad biológica".

36 Ver, entre otros, Cabrera Medaglia, J. A. El impacto de las Declaraciones de Río y Estocolmo sobre la legislación y las políticas ambientales en América Latina. Revista de Ciencias Jurídicas. Universidad de Costa Rica. Vol. 100. San José de Costa Rica, 2003, 306 y 309 s., respectivamente.

37 Así lo hacen explícitamente -mediante el empleo de fórmulas diferentes pero con similar alcance protectivo- la CPer/1979, art. 123; la CCh/1981, art. 19[8'1]; CNic/1986, art. 
vida y dignidad de las personas ${ }^{38}$, imponiendo tanto al "Estado" (o al "poder público") como a la "sociedad" (o a la "coletividad", a los "ciudadanos", a "todos los habitantes" o, en general, a "las personas") $)^{39}$ el deber de respetar, garantizar, proteger o promover este derecho, de contribuir a la protección, conservación o preservación de la naturaleza, así como también de prevenir su contaminación (en beneficio de las generaciones presentes y futuras).

Se trataría de un derecho que la doctrina ubica generalmente dentro de la "tercera generación" de los derechos humanos, es decir, de un derecho subjetivo concebido para todos y cada uno de los hombres, oponible a cualquiera (Estado y/o particulares) y que puede ser ejercido igualmente a nombre de cualquiera (por formar parte generalmente de los denominados intereses "colectivos" o "difusos"); caracterizado asimismo por su "transversalidad" (pues sus principios se proyectan a la totalidad de los respectivos ordenamientos jurídicos $)^{40}$, ya que a través del mismo se protegen además $-v . g r$.- la vida y la salud humana, el equilibrio ecológico y la biodiversidad, así como también la conservación de los recursos naturales, el paisaje e, incluso, los bienes culturales. El reconocimiento constitucional de un derecho con tales características subjetivas y objetivas condiciona el ejercicio de la autonomía individual y, en consecuencia, afecta los demás derechos constitucionales que la presupongan, pues si el derecho a la vida es el prius de todos los demás derechos, el entorno adecuado donde la misma se desarrolla y se ejercen todos los demás derechos del hombre constituye el elemento imprescindible para poder disfrutar de los mismos.

Es así como ya la Constitución chilena de 1981 prescribió que "[1]a ley podrá establecer restricciones específicas al ejercicio de determinados derechos o libertades para proteger el medio ambiente" (art. 19[24]), disposición

60; la CBra/1988, art. 255[pr.]; la CCol/1991, art. 79' la CPar/1992, art. 71' la CPer/1993, art. 2[22]; la CArg/1953-1994, art. 41'1 la CCR/1949-1994, art. 50²; la CUru/1967-1996, art. 47' la CEcu/1998, arts. 23[6] y 86[pr.]; la CMéx1917-1999, art. 45; la CVen/1999, art. 127; la CEcu/2008, art. 14; la CBol/2009, art. 33, y la CRD/2010, art. 66[1y2] y 75[11]. En sentido análogo se ha expresado -en el ámbito del Sistema Interamericano de Derechos Humanos- el "Protocolo Adicional a la Convención Americana sobre Derechos Humanos en materia de Derechos Económicos, Sociales y Culturales" (suscrito el 17 de noviembre de 1988), cuyo artículo 11 dispone que "[t]oda persona tiene derecho a vivir en un medio ambiente sano..." y que los "Estados partes promoverán la protección, preservación y mejoramiento del medio ambiente".

38 Tal como se expresan -con marcado tono antropocéntrico- la CPan/1972-1983-2004, art. 118; la CHon/1982, art. 1453; la CPer/1993, art. 2[22]; la CArg/1853-1994, art. 41 ${ }^{1}$; la CMéx1917-1999, art. $4^{5}$, y la CVen/1999, art. 127.

39 Como hiciera por primera vez la CCub/1976 (art. 27), seguida luego -v.gr.- por la

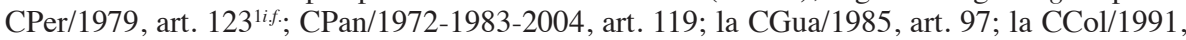
art. 95[8]; la CArg/1994, art. 41'1 la CEcu/1998, art. 97[16]; la CVen/1999, art. 127 y 326; la CUru/1967-1996, art. 47'1 la CEcu/2008, art. 83[6]; la CBol/2009, art. 108[14-16], y la CRD/2010, art. 75[11].

40 Algunas aplicaciones concretas de esta "transversalidad" han sido reconocidas expresamente por la CEcu/2008, arts. 395[2] y 414, y por la CBol/2009, art. 345[2]. 
esta imitada luego por otras cartas constitucionales latinoamericanas ${ }^{41}$. Esta limitación del ejercicio de ciertos derechos y libertades fundamentales (tales como el derecho al desarrollo, la libertad económica, de industria y comercio, de trabajo, etc.) en aras de la protección del medio ambiente fue reiterada luego de manera especial, por la misma Constitución, en relación con el derecho de propiedad (art. 19[8] ${ }^{42}$; introduciendo de esta manera la denominada "función ambiental de la propiedad" (como una derivación de la "función económica y social" de la misma reconocida ya por el "constitucionalismo social"), la que en algunos países de América Latina ha sido objeto -incluso- de particulares desarrollos y aplicaciones por parte de la doctrina, de la jurisprudencia y de la legislación secundaria.

Así, respecto a las elaboraciones doctrinales y jurisprudenciales puede citarse al respecto el caso de Costa Rica -un país con una fuerte vocación ecológica-, en donde, si bien la Constitución no hace referencia expresa a este principio, el mismo ha sido ampliamente utilizado por vía interpretativa $-v . g r .-$ en materia de "propiedad forestal" o para la elaboración de la figura de la "posesión ecológica" (consistente en la realización de actos posesorios -activos u omisivos- encaminados a la conservación de los ecosistemas y a mantener el equilibrio de los mismos), la que es exigida como requisito indispensable para la usucapión de bosques o terrenos ubicados en zonas que hayan sido declaradas áreas silvestres protegidas ${ }^{43}$. Por lo que se refiere, en cambio, al derecho secundario, son dignas de mencionar las limitaciones impuestas al ejercicio del derecho de propiedad por algunas disposiciones de las más modernas codificaciones civiles de Latinoamérica; entre las que pueden citarse las contenidas en el artículo 131.1 CC cubano de 1987 ("El propietario de un terreno puede hacer en él obras, plantaciones y excavaciones, con las limitaciones establecidas en las disposiciones legales, especialmente las relativas a [...] [la] protección del patrimonio nacional y cultural, y a los recursos naturales y el medio ambiente"), en el artículo 1228[1] CC brasileño de 2002 (“... O direito de propriedade deve ser exercido em consonância com as suas finalidades econômicas e sociais e de modo que sejam preservados, de conformidade com o estabelecido em lei especial, a flora, a fauna, as belezas naturais, o equilíbrio ecológico e o patrimônio histórico e artístico, bem como evitada a poluição do ar e das águas") ${ }^{44}$ y en el artículo 240 del

41 Como hicieran, v.gr., la CEcu/1979-1983, art. 19[2]; la CEcu/1998, art. 23[6²], y la CVen/1999, art. 112.

42 Una disposición similar fue prevista también, v.gr., por la CBra/1988, art. 186[II] (en el ámbito de la propiedad rural); la CCol/1991, art. 58²; la CEcu/2008, arts. 31, 66[26], 282 y 321, y la CBol/2009, art. 373.II (en materia de recursos hídricos).

43 Ver a mayor abundamiento, entre otros, Ulate Chacón, E.; Rodríguez Brunett, O. A. y Cabrera Medaglia, J. Derecho agrario y desarrollo sostenible. San José de Costa Rica, 2000, pp. 296 ss.

44 Como una aplicación concreta de estas mismas ideas la doctrina brasileña ha desarrollado 
nuevo Código Civil y Comercial argentino de 2014 (“... El ejercicio de los derechos individuales sobre los bienes [...] debe ser compatible con los derechos de incidencia colectiva. [...] [N]o debe afectar el funcionamiento ni la sustentabilidad de los ecosistemas de la flora, la fauna, la biodiversidad, el agua, los valores culturales, el paisaje, entre otros, según los criterios previstos en la ley especial") ${ }^{45}$.

Asimismo, con el tiempo muchas constituciones latinoamericanas han ido afinando la regulación del derecho humano a un medio ambiente adecuado, preocupándose en particular de algunos de sus componentes específicos y de la introducción de ciertos principios de política ambiental. Entre los primeros pueden señalarse: i) la protección específica de la flora, la fauna, la vida silvestre, el clima, el agua, el aire, el suelo o la tierra, el paisaje, etc. ${ }^{46}$; ii) la conservación de la biodiversidad ${ }^{47}$; y iii) la salvaguardia del patrimonio cultural $^{48}$. Por lo que se refiere a los segundos cabe destacar: i) la creación de zonas geográficas o áreas naturales protegidas ${ }^{49}$; ii) la prohibición de los movimientos transfronterizos de residuos o desechos tóxicos o peligrosos ${ }^{50}$; iii) la regulación del ingreso y/o salida del país de recursos genéticos ${ }^{51} \mathrm{y}$ de los organismos genéticamente modificados ${ }^{52}$; iv) el derecho de infor-

la noción de la "função ambiental do contrato", como un redimensionamiento de la "função social do contrato" reconocida por el artículo 421 CC de 2002, que actúa como una suerte de límite positivo a la autonomía privada (ver, entre otros, Limonta Esteves Grizzi, A. L. Direito ambiental aplicado aos contratos. São Paulo, 2008, 60 ss.).

45 En sentido concordante, pero con un alcance más general, este mismo Código ha dispuesto también en su "Título preliminar" que "[1]a ley no ampara el ejercicio abusivo de los derechos individuales cuando pueda afectar al ambiente y a los derechos de incidencia colectiva en general" (art. 14²).

46 Así, v.gr., pueden verse -aunque con el empleo de diversas fórmulas y con diferente alcance- la CPer/1979, art. 123; la CPan/1972-1983-2004, art. 118; la CGua/1985, art. 97; la CBra/1988, art. 225[1.viI]; CCub/1976-1992, art. 27i.f.; la CMéx/1917-1999, art. 46; la CVen/1999, art. 127; la CUru/1967-1996-2004, art. 472-3; la CEcu/2008, arts. 400-402 y 404-415; la CBol/2009, arts. 348.I y 386-389, y CRD/2010, arts. 15 y $66^{1-2}$.

47 Ver, v.gr., CCub/1976, art. 39[h]; CBra/1988, art. 225[1.II]; CCol/1991, art. 792;

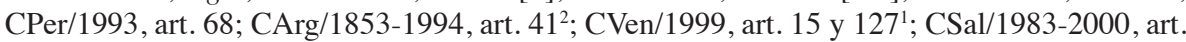
$117^{1}$; CEcu/2008, arts. 400-403, y CBol/2009, arts. 380-383.

48 Ver, v.gr., CGua/1985, art. 60; CCol/1991, arts. 8 y 95[8]; CPar/1992, arts. 38 y 81'; CArg/1853-1994, art. 412; CEcu/2008, arts. 3[7] y 21; CBol/2009, art. 99, y CRD/2010, art. 66[3].

49 Ver, v.gr., CGua/1985, art. 64; CBra/1988, art. 225[4]; CCol/1991, art. 310; CPer/1993, arts. 68 y 69; CEcu/1998, arts. 86[3] y 240; CVen/1999, art. 127'; CEcu/2008, arts. 405 y 407; $\mathrm{CBol} / 2009$, art. 385, y CRD/2010, art. 16.

50 Ver, v.gr., CCol/1991, art. 81'; CPar/1992, art. 8; CArg/1853-1994, art. 41 ${ }^{4} ; \mathrm{CEcu} / 1998$, art. 90; CVen/1999, art. 129 ${ }^{1 \text { iff. }}$ CSal/1983-2000, art. 1173; CEcu/2008, art. 15; CBol/2009, art. 344, y CRD/2010, art. 67[2]; en coincidencia con lo dispuesto por el principio 14 de la Declaración de Río de 1992.

51 Ver, v.gr., CCol/1991, art. 812; CPar/1992, art. 83; CEcu/1998, art. 89; CVen/1999, art. $127^{1}$; CEcu/2008, arts. $14,73,313$ y 400, y CBol/2009, art. 407[11].

52 Ver, v.gr., CEcu/1998, art. 89[3]; CEcu/2008, arts. 15 y 401, y CBol/2009, art. 409. 
mación ${ }^{53}$ y de participación social en la gestión del medio ambiente ${ }^{54}$ (con especial consideración de las comunidades indígenas ${ }^{55}$ ); v) el fomento de la educación medioambiental ${ }^{56}$; vi) la promoción de la cooperación internacional en materia medioambiental (pricipalmente entre países limítrofes o pertenecientes a una misma región) ${ }^{57}$, y vii) la posibilidad de declarar el "estado de excepción" o de "emergencia" no solo por motivos sociales, económicos o políticos (como tradicionalmente se lo ha concebido) sino también en caso de desastres naturales o ecológicos ${ }^{58}$.

Cabe destacar también, en relación con los aspectos sustantivos de la tutela medioambiental, que la mayor parte de las constituciones de América Latina se han ocupado de regular la responsabilidad derivada del daño ambiental, comenzando por la brasileña de 1988, que dispuso en su artículo 225[3] que "[a]s condutas e atividades consideradas lesivas ao meio ambiente sujeitarão os infratores, pessoas físicas ou jurídicas, a sanções penais e administrativas, indipendentemente da obrigação de reparar os danos causados"; en concordancia con lo previsto por el principio 22 de la Declaración de Estocolmo de 1972 y anticipándose de esta manera a lo que luego establecerá también el principio 13 de la Declaración de Río de $1992^{[59]}$.

La mayoría de las constituciones latinoamerianas sancionadas con posterioridad han seguido este modelo: i) afirmando genéricamente la obligación de "responder" por las acciones y omisiones contrarias a la normativa de protección del mediambiente ${ }^{60}$; ii) refiriendo de manera más específica a la obligación de "reparar" ${ }^{1}$ (no faltando, incluso, las que han agregado también

53 Ver, v.gr., CArg/1853-1994, art. 412; CEcu/1998, art. 88; CEcu/2008, art. 395[3], y $\mathrm{CBol} / 2009$, art. 343.

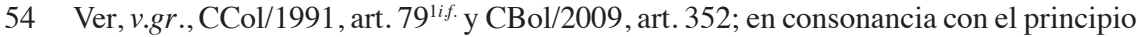
10 de la Declaración de Río de 1992.

55 Ver, v.gr., CCol/1991, art. 330.par.; CArg/1853-1994, art. 75[17]; CEcu/1998, art. 84[5]; CVen/1999, art. 120 ${ }^{1}$; CEcu/2008, art. 57[7], y CBol/2009, art. 30.II[15]; en concordancia, también en esta otra materia, con la Declaración de Río de 1992 (principio 22).

56 Ver, v.gr., la CSal/1983, art. 60²; la CBra/1988, art. 225[1.VI]; la CCol/1991, art. $67^{2}$ y 79²; la CArg/1853-1994, art. 41²; CVen/1999, art. 107; la CEcu/2008, art. 27, y la CBol/2009, art. 80.I.

57 Ver, v.gr., la CCol/1991, art. $80^{2}$ y 289 ; la CVen/1999, arts. 153 y 289 ; la CEcu/2008, art. 416[13]; la CBol/2009, art. 255[II.3], y la CRD/2010, art. 67[5i.f.].

58 Ver, v.gr., la CCol/1991, art. 215; la CVen/1999, art. 337; la CEcu/2008, art. 164, y la $\mathrm{CBol} / 2009$, art. 137. Sobre este particular puede consultarse con provecho AmaYA NaVAS, O. D. El medio ambiente y los estados de excepción. Revista Derecho del Estado. Vol. 1. Bogotá, 1997, 77 ss.

59 Ver, entre otros, Benjamin, A. H. V. Responsabilidade civil pelo dano ambiental. Revista de Direito ambiental. Vol. 9. São Paulo, 1998, 5 ss. En el derecho constitucional europeo la reparación del daño ambiental ya había sido prevista por la Constitución portuguesa de 1976 (art. 66.3) y por la española de 1978 (art. 45.3).

60 Ver, v.gr., la CEcu/1998, art. 87.

61 Ver, v.gr., la CCol/1991, art. 80²; la cCR/1949-1994, art. 50²; la CBol/2009, art. 347.II, y la $\mathrm{CRD} / 2010$, art. 67[5]. 
la obligación de "mitigar" y/o "minimizar" el daño medioambiental ${ }^{62}$ ); iii) dando preferencia -sin perjuicio de la obligación de "resarcir" los daños y perjuicios ocasionados- al deber de "recomponer" o "restaurar" 63 integralmente los ecosistemas afectados; y/o iv) llegando además, algunas de ellas, a afirmar que la responsabilidad en esta materia es de tipo "objetivo" 64 y a disponer la inversión de la carga de la prueba ${ }^{65}$. Asimismo, en conexión con estas disposiciones, varias constituciones de la región han reconocido jerarquía constitucional al "principio de precaución", exigiendo en consecuencia que todas las actividades susceptibles de generar un daño a los ecosistemas deban estar precedidas de una "evaluación del impacto ambiental" (como recomendaran, respectivamente, los principios 15 y 17 de la Declaración de Río de 1992) ${ }^{66}$.

Empero el "constitucionalismo ambiental latinomericano" no se ha contentado con la regulación sustantiva del derecho al medio ambiente, sino que ha dedicado también un amplio espacio a las garantías adjetivas necesarias para hacerlo efectivo (tal como recomendó el principio 10 de la Declaración de Río). En efecto, tratándose para la casi totalidad de las cartas constitucionales latinoamericanas de un derecho fundamental, la protección del medio ambiente estaría garantizada -en principio- por el mecanismo constitucional previsto para la tutela de este tipo de derechos (denominado habitualmente, en Latinoamérica, "acción" o "recurso de amparo" ${ }^{67}$, el que sin embargo podría presentar el inconveniente de que por lo general el mismo está concebido para la tutela de los derechos individuales.

En efecto, en la tradicion de derecho romano (a la cual pertenecen los ordenamientos de América Latina) ${ }^{68}$, las cosas que hoy son calificadas como

62 Tal como hacen, v.gr., la CEcu/2008, art. 396 y la CBol/2009, art. 347.

63 Es decir, la obligación -cuando ello sea posible- de restablecer las cosas al estado anterior a la producción del daño (lo que constituye el principal interés del derecho ambiental), tal como disponen expresamente -v.gr.- la CPar/1992, art. 84; la CArg/1853-1994, art. 41 1i.f., y la CEcu/2008, art. 396.

64 Ver, v.gr., la CEcu/2008, art. 396 y la CRD/2010, art. 67[5].

65 Ver, v.gr., la CEcu/2008, art. 397[1i.f.].

66 Ver, v.gr., la CBra/1988, art. 225[1.IV]; la CEcu/1998, art. 91²; la CVen/1991, art. 129; la CEcu/2008, art. 396, y la CBol/2009, art. 345[2].

67 Algunas leyes fundamentales del subcontinente latinoamericano se encargaron incluso de establecer expresamente la aplicación de este tipo de protección general de los derechos constitucionales también a la tutela del medio ambiente (o más, genéricamente, a los derechos e intereses colectivos o difusos); tal como hizo por primera vez la CCh/1981 (art. 202 , en la que recibe el nombre de "recurso de protección"), seguida luego -v.gr.- por la CArg/1853-1994 (art. 43²), la CEcu/1998 (art. 95³), la CVen/1999 (art. 261') y la CRD/2010 (art. 72).

68 Como nos recuerdan AcuÑa SolorZano, G. M. Los interdictos populares como instrumento de tutela a las res in usu publico en el Derecho romano y su influencia en las codificaciones latinoamericanas. Con atención a la tutela ambiental. Roma e America. Diritto romano comune. Vol. 25. Modena-Bogotá, 2008, 60 ss. y Trisciuoglio, A. Tutela del Medio Ambiente (Roma, Europa, América Latina). En Álvarez LeDESMA, M. I. y CiPPITAN, R., coords. Diccionario analítico de Derechos Humanos e integración jurídica. Roma-Perugia-México, D. F., 2013, 697 ss. 
"bienes ambientales" habían sido incluidas en la categoría de las res publicae in usu publico (I. 3,19,2; D. 18,1,6 pr. [POMPONIO]; D. 50,16,17 pr. [UlPIANo]), es decir, en la de las cosas pertenecientes al populus Romanus pero destinadas al uso colectivo (cuya titularidad no corresponde al Estado-persona, sino a todos los ciudadanos o al Estado-comunidad), o en aquella de las res communes omnium naturali iure (D. 1,8,2,1 [MARCIANO]; I.1,2,1), o sea de las cosas que pertenecen a todos los hombres por derecho natural. Esta tradición, mantenida por el derecho común ibérico (Siete Partidas 3,28,3; 3,28,4; $3,29,7)$ pero abandonada luego por el derecho moderno debido al influjo de la cultura iuspositivista anglosajona (de corte "economicista-privatista" y "estatualista-positivista" ${ }^{69}$, fue retomada con fuerza por el "constitucionalismo ambiental latinoamericano" 70 .

Es por ello que, teniendo en cuenta esta particular naturaleza reconocida a los denominados "bienes ambientales" (res publicae in usu publico o res communes omnium) y a los correspondientes intereses en juego ("colectivos" o "difusos" $)^{71}$, muchas constituciones de la región han ampliado la legitimación activa para reclamar judicialmente la protección del medio ambiente a "[t]oda persona" (natural o jurídica, individualmente o en grupo) ${ }^{72}$, llegando además algunas de ellas a regular expresamente para estos casos la denominada "acción popular" (actio popularis) ${ }^{73}$. Se retoma aquí también, para la defensa del medio ambiente, la tradición romano-ibérica de las "acciones [o, mejor dicho, 'interdictos'] populares" (D. 47,23,1 [PAuLo]; Siete Partidas $3,32,3)^{74}$ que la codificación civil europea dejó de lado, pero que en cambio se mantuvo en la latinoamericana a través de su "transfusión" al Código Civil chileno de 1855 (arts. 948-950, 2328, 2333 y 2334) y, de allí, a los demás códigos que adoptaron su texto en todo o en parte (v.gr., el ecuatoriano de

69 Ver, en este sentido, Lobrano, G. Uso dell'acqua e diritto nel Mediterraneo. Uno schema di interpretazione storico sistematica e de iure condendo.Diritto@Storia.Rivista internazionale di scienze giuridiche e tradizione romana. Sassari, 2004, p. 6.

70 Al respecto resulta paradigmático el artículo 349.I CBol/2009, que dispone: "Los recursos naturales [categoría que, según el art. 348.I, está integrada por "los minerales en todos sus estados, los hidrocarburos, el agua, el aire, el suelo y el subsuelo, los bosques, la biodiversidad, el espectro electromagnético y todos aquellos elementos y fuerzas físicas susceptibles de aprovechamiento"] son de propiedad y dominio directo, indivisible e imprescriptible del pueblo boliviano, y corresponderá al Estado su administración en función del interés colectivo".

71 Esta ampliación de la legitimación activa a "toda [o a "cualquier"] persona" constituye el lógico reverso del deber (también general, colectivo o difuso) impuesto a la "sociedad" (o a la "coletividade", a los "ciudadanos", a "todos los habitantes" o a "las personas" en general) de proteger el medio ambiente (ver supra nota 39).

72 Ver, v.gr., la CPar/1992, art. 38; la CArg/1853-1994, art. 412; la CCR/1949-1994, art. $50^{1}$, y CEcu/1998, art. $91^{3}$, y la CEcu/2008, arts. 86[1] y 88.

73 Ver, v.gr., la CBra/1988, art. 5[LXXIII]; la CCol/1991, art. 88' ${ }^{1}$, y la CBol/2009, arts. 135 y 136 (en perfecta sintonía con lo dispuestos en el art. 349.I transcrito supra nota 70).

74 Como también observan AcuÑa Solorzano, G. M. Los interdictos populares, cit., 69 ss. y Trisciuoglio, A. Tutela del Medio Ambiente, cit., 697 ss. 
1858 , arts. 1012-1014, 2255, 2260 y 2261; el colombiano de 1859-1873, arts . 1005-1007, 2355[2], 2359 y 2360; el salvadoreño de 1859, arts. 949-951, 2079,2084 y 2085 ; el nicaragüense de 1904, arts. 1826 y 1828; el hondureño de 1906, arts. 927-929, y el panameño de 1916, arts. 625-627) ${ }^{75}$.

Por último, cabe señalar que muchas constituciones latinoamericanas han confiado también la defensa de los "bienes ambientales" a ciertos órganos estatales encargados de tutelar los intereses de la colectividad (como es el caso del Ministerio Público ${ }^{76}$ o, más específicamente, del Defensor del Pueblo $^{77}$ ) o, directamente, a órganos jurisdiccionales especializados en materia medioambiental ${ }^{78}$. Igualmente se advierte aquí una cierta línea de continuidad con la tradición de derecho romano, pues también en ella la tutela de los hoy llamados "bienes ambientales" -al menos durante la República y el Principado- era mixta, es decir, estaba en manos tanto de los particulares (a través de las ya referidas actiones populares y de los interdicta popularia) como de los magistrados (especialmente los ediles, quienes tenían el encargo de garantizar la salubridad de los lugares públicos más frecuentados, como era el caso $-v . g r$.- de los baños públicos $)^{79}$.

\section{DE LA PROTECCIÓN DEL DERECHO HUMANO AL MEDIO AMBIENTE} AL RECONOCIMIENTO DE LOS DERECHOS DE LA NATURALEZA

\section{La creación de un nuevo paradigma de protección ecológica: los derechos de la naturaleza}

La protección -más o menos articulada- del derecho humano a un medio ambiente sano y ecológicamente equilibrado, prevista por la casi totalidad de las constituciones latinoamericanas, no ha logrado -sin embargo- eliminar del todo la depredación de la naturaleza así como tampoco la aplicación del modelo extractivista a sus recursos, en atención a que -como hemos

75 Dentro de esta misma orientación podemos citar, asimismo, el Anteproyecto de Código modelo de los procesos colectivos elaborado por el Instituto Iberoamericano de Derecho Procesal, cuyo texto definitivo fuera aprobado en Caracas el 28 de octubre de 2004 (ver, sobre este particular, Pellegrini Grinover, A. Proyecto de Código Modelo de Procesos Colectivos para Iberoámerica. Roma e America. Diritto romano comune. Vol. 17. Modena-Bogotá, 2004, 257 ss.).

76 Ver, v.gr., la CBra/1988, art. 129[III]; la CCol/1991, art. 277[7]; la CPar/1992, art. 268[1], y la CBol/2009, art. 136.II.

77 Ver, v.gr., la CArg/1853-1994, art. 43²; la CVen/1999, art. 280'1 la CBol/2009, art. 136. II, y la CRD/2010, art. 191 .

78 Como es el caso de la "jurisdicción agroambiental" instituida por la CBol/2009 (arts. 186-189), la que junto con la "jurisdicción ordinaria" y con la "jurisdicción indígena originaria campesina” conforman el Órgano Judicial boliviano (ver Título II: "Órgano Judicial y Tribunal Constitucional Plurinacional").

79 Sobre este otro particular ver, nuevamente, TrisciuogLIO. Tutela del Medio Ambiente, cit., 693 ss. 
señalado- este derecho sigue estando concebido principalmente en función de los intereses de las personas; ya que la exigencia de que el entorno deba guardar ciertos niveles de calidad no está impuesta a favor de las especies que en él viven o de la integridad de los ecosistemas en sí considerados, sino para asegurar el bienestar del ser humano y defender la idea de una historia lineal orientada al progreso de la humanidad y de un desarrollo de la misma basado esencialmente en el crecimiento económico ${ }^{80}$.

Esta concepción marcadamente "antropocéntrica" y "economicista/utilitarista" constituye una herencia de la modernidad, la cual (siguiendo la "lógica cartesiana" ${ }^{81}$ ) transformó la naturaleza en "ambiente" -es decir, en "lo que rodea" al hombre-, colocándolo en el centro de la misma y convirtiéndolo en su amo y señor ${ }^{82}$. Como consecuencia de ello únicamente la persona (natural o jurídica) puede ser "sujeto/titular" de una relación jurídica, mientras que la naturaleza solo puede constituir "objeto" de la misma; por lo que se la protege en tanto en cuanto esté directamente vinculada a la salud o al deleite del hombre, o en razón de ser susceptible de apropiación (en forma individual o colectiva) por las personas, o porque sirve para alimentar procesos productivos destinados a satisfacer las necesidades de las generaciones presentes o futuras de seres humanos ${ }^{83}$.

80 Como agudamente observa Gudynas, E. La ecología política del giro biocéntrico en la nueva Constitución de Ecuador. Revista de Estudios Sociales. Vol. 32. Bogotá, abril de 2009, 38 y 44.

81 Según la cual el hombre, en cuanto único ser dotado de cogito (es decir, capacidad de autoconciencia), es el señor absoluto de la naturaleza no humana y su misión progresista y racional consiste en dominarla, mientras que los animales son "máquinas" (desposeídas de alma) y, por lo tanto, están destinados a ser objeto del dominio humano. Sobre las ideas de ReNÉ DesCARTES (1596-1650) en esta materia remitimos, entre otros, a ZAFFARONI, E. R. La Pachamama y el humano. En Acosta, A. y Martínez, E., comps. La naturaleza con derechos. De la filosofía a la política. Quito, 2011, 36 ss.

82 Una acusación similar ha sido lanzada también al pensamiento judío-cristiano, argumentándose que desde el relato del Génesis, en el que se invita al hombre a "dominar" la tierra $(G n 1,28)$, se favorecería la explotación salvaje de la naturaleza. Empero esta interpretación de las Sagradas Escrituras ha sido rechazada recientemente por el papa FRANCISCO en su Laudato si'. Carta Encíclica sobre el cuidado de la casa común (Città del Vaticano, Libreria Editrice Vaticana, 2015), párs. 66 y 67, 63 s.; pár. 68, 65 s.; pár. 69, 66 s.; pár s. 81 s., 77; y pár. 118, 111; etc.

83 Ver la crítica formulada a esta concepción, entre otros, por MEIER, H. El derecho ambiental y el nuevo milenio, cit., 46 ss.; Maliré, É. y de Ávila Aguiar CoImbra, J. Antropocentrismo x ecocentrismo na Ciência jurídica. Revista de Direito ambiental. Vol. 36. São Paulo, 2004, 9 ss. y, de manera particular, GudYNAs, E. Los Derechos de la Naturaleza y la construcción de una justicia ambiental y ecológica en Ecuador. En Espinosa Gallegos-Anda, C. y Pérez Fernández, C., eds., Los derechos de la Naturaleza y la naturaleza de sus derechos. Quito, 2011,98 s., quien destaca que de esta manera la naturaleza es entendida como "capital natural", bajo la esperanza de que la incorporación de la fauna, la flora y los ecosistemas a los mercados generaría una efectiva conservación de los mismos. Desde este punto de vista la conservación de los seres vivos no sería un asunto de derecho, sino que se convertiría en una cuestión económica, donde 
Empero esta visión dual del mundo (hombre/naturaleza), que justifica la apropiación material del entorno con fundamento en una lógica de jerarquía y dominación (del primero sobre la segunda), fue superada por la Constitución ecuatoriana de 2008 a través del reconocimiento expreso de derechos a la naturaleza, con independencia de las valoraciones humanas, operándose así por primera vez en la historia del constitucionalismo lo que algunos han dado en llamar el "giro biocéntrico" del denominado "nuevo constitucionalismo andino" ${ }^{84}$. Es por ello que puede afirmarse que, así como el constitucionalismo latinoamericano ya había legado al universal -mediante la Constitución mexicana de Querétaro de 1917- la categoría de los "derechos económicos y sociales", ahora el mismo hace lo propio - a través de la Constitución ecuatoriana de Montecristi de 2008- respecto a los "derechos de la naturaleza", dando de esta manera un salto de calidad, del "ambientalismo", a un vedadero "ecologismo constitucional" 85 .

Así, ya en el Preámbulo de la Constitución de la República de Ecuador de 2008 se dice que "[c]elebramos la naturaleza, la Pacha Mama, de la que somos parte y que es vital para nuestra existencia", agregando seguidamente que se decide construir una "nueva forma de convivencia ciudadana, en diversidad y armonía con la naturaleza, para alcarzar el buen vivir, el sumak kawsay" (ver infra II.2). Luego en el artículo 10, segundo párrafo, se establece que "[1]a naturaleza será sujeto de aquellos derechos que le reconozca la Constitución", los que son desarrollados en el Capítulo vil del Título II, en el cual se dispone que "[1]a Naturaleza o Pachamama, donde se reproduce y realiza la vida", tiene derecho: i) "a que se respete integralmente su existencia y el mantenimiento y regeneración de sus ciclos vitales, estructura, funciones y procesos evolutivos" (art. 71); ii) "a la restauración" integral, la que es "independiente de la obligación que tienen el Estado y las personas naturales o jurídicas de indemnizar a los individuos y colectivos que dependan de los sistemas naturales afectados" (art. 72); y, iii) a que el Estado aplique "medidas de precaución y restricción para las actividades que puedan conducir a la extinción de especies, la destrucción de ecosistemas o la alteración perma-

se debería demostrar su relevancia para las economías nacionales (en una "lógica" parecida a la que hemos visto supra I.1 en lo que respecta a la explotación de los recursos naturales).

84 Ver, una vez más, GudYNAs, E. La ecología política del giro biocéntrico, cit., 38 s., quien recuerda como precursores de las llamadas "perspectivas biocéntricas" (que ponen el acento en el valor intrínseco de las otras especies, de los sistemas y de los procesos naturales), a Henry David Thoreau (1817-1862, Walden, Boston, 1854), en el siglo XIX, y a Aldo Leopold (1887-1948, A Sand County Almanac, New York, 1949), a mediados del siglo xx, hasta el decisivo empuje promovido desde la década de 1970 por filósofos como ARNe NÆSS (1912-2009, Ecology, community, and lifestyle: outline of an ecosophy, New York, 1989), quienes bajo la corriente de la denominada "ecología profunda" ( una postura biocéntrica no solo desde una reacción frontal a la modernidad, sino también desde las cosmovisiones de los pueblos originarios de América Latina.

85 Tal como observa ZaFfaroni. La Pachamama y el humano, cit., 106. 
nente de los ciclos naturales", incluida la prohibición de que se introduzcan "organismos y material orgánico e inorgánico que puedan alterar de manera definitiva el patrimonio genético nacional" $\left(\right.$ art. 73) ${ }^{86}$.

El nuevo modelo ecológico introducido por la vigente ley fundamental ecuatoriana fue imitado inmediatamente por otro país andino, la República Plurinacional de Bolivia, cuya Constitución de 2009 refiere también en el Preámbulo a la naturaleza, al declararse en el mismo que, "[c]umpliendo con el mandato de nuestros pueblos, con la fortaleza de nuestra Pachamama y gracias a Dios, refundamos Bolivia"; y más adelante en el artículo 33 dispone que "[1] as personas tienen derecho a un medio ambiente saludable, protegido y equilibrado. El ejercicio de este derecho debe permitir a los individuos y colectividades de las presentes y futuras generaciones, además de otros seres vivos, desarrollarse de manera normal y permanente". Si bien este texto continúa ocupándose principalmente del derecho humano al medio ambiente, el mismo se refiere además "a otros seres vivos" 87 , lo que importa reconocerles también a ellos la calidad de sujetos de derecho, tal como ha sido confirmado luego por la legislación secundaria boliviana. En efecto, la Ley 071 (21 de diciembre de 2010) ${ }^{88}$, cuyo principal objeto fue "reconocer los derechos de la Madre Tierra ${ }^{89}$, así como las obligaciones y deberes del Estado Plurinacional y de la sociedad para garantizar el respeto de estos derechos" (art. 1), le otorgó a la misma el cáracter de "sujeto colectivo de interés público" (art. 5) y le reconoció expresamente los siguientes derechos: i) a la vida; ii) a la diversidad de la vida; iii) al agua; iv) al aire limpio; v) al equilibrio; vi) a la restauración; vii) a vivir libre de contaminación (art. 7) ${ }^{90}$.

86 Sobre el significado de estas disposiciones ver, en general,PrIETo MéndEZ, J. M.Derechos de la Naturaleza. Fundamentos, contenido y exigibilidad jurisdiccional. Quito, 2013, 115 ss.

87 Una expresión similar se repite luego en el artículo 108[16] CBol/2009, cuando se dispone que "[s]on deberes de las bolivianas y los bolivianos: [...] Proteger y defender un medio ambiente adecuado para el desarrollo de los seres vivos".

88 Esta ley reconoce su fuente en el "Proyecto de Declaración de los Derechos de la Madre Tierra" aprobado por unanimidad en la primera "Cumbre Mundial de los Pueblos sobre Cambio Climático y los Derechos de la Madre Tierra" (Cochabamba, 19-22 de abril de 2010). Ambos textos sirvieron luego como modelo para la elaboración del "Proyecto de Ley marco de los Derechos de la Madre Tierra" votado por el Parlamento Latinoamericano (PARLATINO) el 19 de octubre de 2013.

89 Esta misma ley define a la naturaleza como "el sistema viviente dinámico conformado por la comunidad indivisible de todos los sistemas de vida y los seres vivos, interrelacionados, interdependientes y complementarios, que comparten un destino común" (art. $3^{1}$ ), aclarando además que los "sistemas de vida" "[s]on comunidades complejas y dinámicas de plantas, animales, micro organismos y otros seres y su entorno, donde interactúan comunidades humanas y el resto de la naturaleza como una unidad funcional, bajo la influencia de factores climáticos, fisiográficos y geológicos, así como de las prácticas productivas, y la diversidad cultural de las bolivianas y los bolivianos, y las cosmovisiones de las naciones y pueblos indígena originario campesinos, las comunidades interculturales y afrobolivianas" (art. 4).

90 Sin perjuicio de precisar, en el artículo 5i.f., que "[1]os derechos establecidos en la presente Ley, no limitan la existencia de otros derechos de la Madre Tierra". 
En honor a la verdad, no se trata de una concepción totalmente nueva pues ella está presente ya en las tradiciones mantenidas por casi todos los pueblos ancestrales alrededor del mundo, y de manera particular en las cosmovisiones de las naciones y pueblos indígenas originarios de América Latina (así como también en las traídas desde África por la población de color), para las cuales la "Naturaleza/Pacha Mama/Madre Tierra" tiene un fuerte enraizamiento en lo sagrado (no ya en el sentido de divino sino en el de merecedor de respeto y cuidado) y es considerada un ser vivo integrado por un conjunto innumerable de seres vivientes $(v . g r$., plantas, animales, minerales, aire, tierra, agua e incluso, también, el hombre $)^{91}$, los que coexisten en una íntima "relacionalidad" (de "correspondencia", "complementariedad", "reciprocidad" y "ciclicidad") no solamente entre ellos mismos sino también con el $\operatorname{cosmos}^{92}$. En efecto, según el pensamiento o la filosofía andina el ser humano, antes que ser racional y productor, es un ente natural que forma parte de la naturaleza, como un elemento más de la misma, relacionado por medio de un sinnúmero de nexos vitales con el conjunto de fenómenos naturales (astronómicos, meteorológicos, geológicos, zoológicos, botánicos, etc.) ${ }^{93}$.

Cabe recordar también que ya en la concepción jurídica romana, conservada en el Corpus iuris civilis y receptada en el derecho de América Latina a través del derecho común ibérico, el ius se articula en tres grandes esferas concéntricas de las cuales la más amplia y antigua es la del ius naturale (el cual "non humani generis proprium est, sed omnium animalium"/"no es privativo del género humano, sino de todos los animales"), al que siguen luego la del ius gentium y la del ius civile (I. 1,2 pr.; D. 1,1,1,3-4 [UlPIANo]; Siete Partidas 1,1,2). En efecto, son varios los fragmentos de la codificación

91 Tal como lo ha reconocido también la ciencia desde hace ya más de treinta y cinco años gracias al trabajo de Lovelock, J. E. Gaia. A New Look at Life on Earth. Oxford, 1979. En este mismo sentido podemos citar además otros pensadores contemporáneos, como $-v \cdot g r$. - el norteamericano STONE, CHr. Should Trees Have Standing? Toward Legal Rights for Natural Objects, Southern California Law Review. Vol. 45. Los Angeles, 1972, 450 ss.; el chileno StuTzin, G. Un imperativo ecológico: reconocer los Derechos de la Naturaleza, Ambiente y Desarrollo. Vol. I (1). Santiago de Chile, diciembre 1984, 97 ss.; el belga Ost, F. La nature hors la loi. L'écologie à l'épreuve du droit. Paris, 1995; el austroamericano F. CAPRA. The Web of Life: A New Scientific Understanding of Living Systems. New York, 1997; el sudafricano Cullinan, C. Wild Law. A Manifesto for Earth Justice. Cape Tawn, 2002, y el brasileño Boff, L. Do iceberg ao Arca de Noé. Petrópolis, 2002.

92 Sobre el significado y alcance de estos tipos de relaciones en la cosmovisión andina remitimos a la obra fundamental del filósofo y teólogo suizo Estermann, J. Filosofía andina. Estudio intercultural de la sabiduría autóctona andina. Quito, 1998, pp. 98 ss. y pp. 114 ss.

93 Ver en este sentido, entre otros, PICARI, N. Naturaleza y territorio desde la mirada de los pueblos indígenas. En Acosta, A. y MARTínez, E., comps. Derechos de la Naturaleza. El futuro es ahora. Quito, 2009, 33 ss.; Llasag Fernández, R. Derechos de la Naturaleza: una mirada desde la filosofía indígena y la Constitución. En Espinosa Gallegos-Anda, C. y Pérez Fernández, C., eds. Los derechos de la Naturaleza y la naturaleza de sus derechos, cit., 78 ss.; MARTínez, E. Prólogo. En Acosta, A. y Martínez, E., comps. La naturaleza con derechos, cit., 9 ss., y Ávila SANTAMARÍA, R. El derecho de la naturaleza: fundamentos. Ibidem, 189 ss. 
justinianea (I. 1,2,2; D. 1,1,4-5; D. 40,11,2; Nov. 74; Nov. 78; Nov. 89) en los que se presume la existencia de una fase "histórica" de imperio exclusivo del ius naturale, la que coincidiría con la edad originaria o "inicio feliz de la historia" de la humanidad (una especie de "edad de oro", anterior a las luchas y divisiones producidas por la sociedad), caracterizada por la conciencia de pertenecer todos los hombres y los demás seres vivos a una misma naturaleza (así como también por la ausencia de la guerra, la esclavitud y la propiedad privada, introducidas sucesivamente por los hombres) ${ }^{94}$.

En el derecho contemporáneo, un paso intermedio hacia la consagración de la categoría de los derechos de la naturaleza había sido dado ya desde finales del siglo XVIII a través el reconocimiento de derechos a los animales, sobre todo por parte de la legislación mediante la cual se criminalizó el maltrato o la crueldad inferida a los mismos, a los que -más allá de la discusión acerca del bien jurídico tutelado en este tipo de delito- se les habría reconocido la misma sensibilidad que tienen los humanos frente al dolor ${ }^{95}$. Mucho más cercano en el tiempo, la presión de la corriente animalista condujo incluso a la "liberación" de los animales de la condición de "cosas" por parte de los códigos civiles del área germánica; tal como se desprende de las disposiciones introducidas en el ABGB austriaco en 1988 (par. 285a), en el BGB alemán en 1990 (par. 90a) y en el zGB suizo en 2002 (art. 641a), en las que se estableció expresamente que los "animales no son cosas" y que "serán tutelados mediante leyes especiales" (sin perjuicio de que "se les apliquen [por analogía] los preceptos correspondientes a las cosas en la medida que no se disponga lo contrario"). En América Latina parece colocarse en esta misma línea la reciente Ley colombiana 1774 (6 de enero de 2016), la que también establece que los animales "no son cosas" (art. 1) e introduce en el artículo 655 CC (que define las cosas muebles) un parágrafo en el que se les reconoce "la calidad de seres sintientes" (art. 2).

Asimismo, basándose en argumentos evolucionistas, éticos, históricos y hermenéuticos, un grupo de científicos, filósofos y juristas ${ }^{96}$ ha defendido la extensión a los grandes primates (chimpancés, gorilas, orangutanes, etc.) de ciertos derechos fundamentales como el derecho a la vida, a la protección de la libertad individual y a la prohibición de la tortura, habiéndose llegado incluso

94 En esta materia resulta de lectura obligatoria la monografía de ONIDA, P. P. Studi sulla condizione degli animali non umani nel sistema giuridico romano. Torino, 2012, 71 ss., y 119 ss.

95 Principalmente desde los trabajos de Jeremy Bentham (1748-1832, An Introduction to the Principles of Morals and Legislation. London, 1780, Cap. 17.1: Borderline between Private Ethics and the Art of Legislation), tal como nos recuerda ZAFFArONI. La Pachamama y el humano, cit., 39 , y 45 ss.

96 Entre los que se destacan Singer, P. Animal Liberation. New York, 1975, y Regan, T. The Case for Animal Rights. Los Angeles, 1983. 
a la elaboración de una "Declaración de los Grandes Simios" 97 . Al respecto reviste particular interés la sentencia dictada el 18 de diciembre de 2014 por la Sala II de la Cámara Federal de Casación Penal de la República Argentina (Causa CCC 68831/2014/CFC1 "Orangutana Sandra s/ recurso de casación s/ habeas corpus"), en la que se concedió una acción de habeas corpus intentada por la Asociación de Funcionarios y Abogados por los Derechos de los Animales (AFADA) a favor de una orangutana que se encontraba en cautiverio en el zoológico de la Ciudad Autónoma de Buenos Aires desde hacía más de 30 años, reconociéndole al animal, "a partir de una interpretación dinámica y no estática" ("principio de progresividad de los derechos"), la calidad de "sujeto no humano titular de derechos"

Ahora bien, la "sustantivación" de la naturaleza por parte del denominado "nuevo constitucionalismo andino" representa el intento de superar los alcances de la protección internacional del medio ambiente al adoptar un enfoque "ecosistémico" de la problemática ambiental que por primera vez ampara en forma vinculante los derechos de todos los seres vivientes, imponiéndole al Estado el deber genérico de garantizarlos y a los ciudadanos la responsabilidad en caso de vulnerarlos. Desde esta nueva perspectiva dicho reconocimiento constituye un desesperado llamado de atención a la comunidad internacional en un contexto geopolítico en el que los últimos instrumentos internacionales en materia medioambiental ( $v . g r$., el Protocolo de Kyoto de 1998 y el Acuerdo de Copenhague de 2009) han fracasado como consecuencia de haber prevalecido los intereses económicos de los países industrializados.

Empero es necesario aclarar que el reconocimiento de los derechos de la "Naturaleza/Pacha Mama/Madre Tierra" no implica negar ni anular el derecho humano a un ambiente adecuado ${ }^{99}$, sino que ambas categorías de derechos fundamentales (biocéntrica, la primera, y antropocéntrica, la segunda) pueden discurrir en forma paralela y, en cierta medida, se necesitan y complementan mutuamente, por lo que consideramos que deben ser articuladas desde el punto de vista de la política y de la gestión ambiental cuando exista una superposición entre ellas. En este sentido ya la Carta Política de Ecuador de 2008 estableció un parámetro para el supuesto de que los derechos humanos y los derechos de la naturaleza entren en colisón al disponer que "[e]n caso de

97 Sobre la cual ver CAVAlieri, P. y Singer, P., eds. The Great Ape Project: Equality Beyond Humanity. New York, 1993.

98 Ver el comentario a la misma de ONIDA, P. P. Il problema della personalità degli animali: il caso dell'orango Sandra, Roma e America. Diritto romano comune. Vol. 36, Modena-Bogotá, 2015.

99 Pues, como bien señala Benjamin, A. H. V. A natureza no direito brasileiro: coisa, sujeito ou nada disso. Nomos. Revista do Programa de Pós-graduação em Direito da UFC [Universidade Federal do Ceará]. Vol. 31 (1). Fortaleza, 2011, 90, “[a]s correntes que rejeitam o antropocentrismo não são misantrópicas, isto é, anti-homem. O que elas combatem é o chauvinismo humano, a ficção insistente - negada pela Ciência - de enxergar os seres humanos como entidades apartadas da natureza". 
duda sobre el alcance de las disposiciones legales en materia ambiental, éstas se aplicarán en el sentido más favorable a la protección de la naturaleza" (art. 395[4]). Este criterio hermenéutico (denominado "principio pro natura") ha sido previsto también por la Ley boliviana 071 de 2010, de Derechos de la Madre Tierra, al establecer que "[e]l ejercicio de los derechos individuales están limitados por el ejercicio de los derechos colectivos en los sistemas de vida de la Madre Tierra, cualquier conflicto entre derechos debe resolverse de manera que no se afecte irreversiblemente la funcionalidad de los sistemas de vida" (art. 6, segundo párrafo) ${ }^{100}$.

Hay que mencionar que el reconocimiento de los derechos de la naturaleza implica además, como sucede respecto a cualquier otro derecho fundamental, la activación de garantías efectivas y de materialización de los mismos. Es así que se ha reconocido a la "Naturaleza/Pacha Mama/Madre Tierra" la posibilidad de exigir a las autoridades públicas la protección de sus propios derechos, para lo cual la misma podrá ser representada por cualquier persona, comunidad, pueblo o nacionalidad; admitiéndose de esta manera, también para estos derechos, una suerte de "acción popular" (tal como disponen expresamente los arts. 11.1, 71 y $86.1 \mathrm{CP}$ ecuatoriana de 2008 y $34 \mathrm{CP}$ boliviana de 2009). Este mecanismo de garantía obviamente no descarta la creación-asimismo- de instituciones jurídicas encargadas especialmente de la defensa de esta otra categoría de derechos, como es el caso de la Defensoría del Ambiente y la Naturaleza o el Defensor del Pueblo, en Ecuador ${ }^{101}$, o la Defensoría de la Madre Tierra, en Bolivia ${ }^{102}$.

Incluso se ha llegado a proponer la creación de un tribunal internacional con jurisdicción universal o extraterritorial, como el que ya existe para los crímenes de lesa humanidad ${ }^{103}$. Recientemente esta propuesta fue reiterada por la Declaración final de la segunda Conferencia Mundial de los Pueblos sobre Cambio Climático y Defensa de la Vida (Cochabamba, 12 de octubre de 2015), en la que se dispuso que: i) "Se deberá crear un Tribunal Internacional de Justicia Climática y de la Madre Tierra" (par. 8.3); ii) "En tanto se constituya [... este Tribunal, se deberá] acudir a la Corte Internacional de

100 Ver, sobre este otro particular, APARICIO WILHELMI, M. Nuevo constitucionalismo, derechos y medio ambiente en las Constituciones de Ecuador y Bolivia. Revista General de Derecho Público Comparado. Vol. 9. Madrid, julio 2011, 17 s.

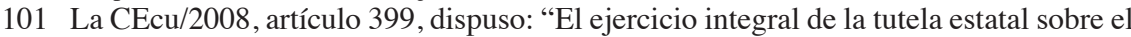
ambiente y la corresponsabilidad de la ciudadanía en su preservación, se articulará a través de un sistema nacional descentralizado de gestión ambiental, que tendrá a su cargo la defensoría del ambiente y la naturaleza". Sin embargo, el nuevo Código Orgánico General de Procesos de 2015 establece que "[1]a naturaleza podrá ser representada por cualquier persona natural o jurídica, colectividad o por el Defensor del Pueblo, quien además podrá actuar por iniciativa propia" (art. $\left.38^{1}\right)$.

102 Creada en Bolivia por la ya referida Ley 071 de Derechos de la Madre Tierra de 2009 (art. 10).

103 Ver, entre otros, Prieto Méndez. Derechos de la Naturaleza, cit., 181 ss. 
Justicia de La Haya, fortaleciendo el marco jurídico internacional ambiental existente, con la finalidad de sancionar a los Estados o los Grupos de Poder/ Transnacionales que contaminen y provoquen el cambio climático por acción u omisión, o cometan delitos o crímenes climáticos o ambientales que atenten contra los derechos de la Madre Tierra y la humanidad" (par. 8.4).

Por último, cabe destacar que pudiendo revestir la naturaleza la condición de "tercero agredido", cuando se la ataque ilegítimamente estaría autorizado también el ejercicio de la legítima defensa en su favor ("legítima defensa de un tercero"), mediante el empleo de medios de lucha no violentos ( $v . g r$., sentadas, colocación de obstáculos al avance de maquinarias de desmonte o escavadoras, etc.), los que serán considerados conductas lícitas en la medida que sean defensivas de agreciones ilegítimas inferidas a la misma ${ }^{104}$.

\section{Una alternativa al modelo capitalista de desarrollo: el ideal amerindio del "buen vivir"/"vivir bien"}

El reconocimiento de los derechos de la "Naturaleza/Pacha Mama/Madre Tierra" es en realidad el punto de partida fundamental hacia un modelo alternativo de vida que el "nuevo constitucionalismo andino" de alguna manera promueve y que se expresa a través del principio ético-moral básico del "buen vivir" (según el Preámbulo y el art. [5] CP ecuatoriana de 2008) o del "vivir bien" (de acuerdo al Preámbulo y al art. 8.I CP boliviana de 2009); tomado también de la cultura ancestral de los pueblos originarios sudamericanos ${ }^{105}$ y que constituye una manifestación más del reconocimiento del pluralismo sociocultural, nacional, político y jurídico llevado a cabo por estas constituciones ${ }^{106}$, con el propósito deliberado de emprender una transformación

104 Así se expresa Zaffaroni. La Pachamama y el humano, cit., p. 134. Sin embargo, la respuesta habitual de los Estados a este tipo de resistencia ha sido la criminalización de estas conductas; llegando muchas veces los defensores de la naturaleza a ser acusados por destrucción de la propiedad, por sabotaje e, incluso, por terrorismo (como observa MARTínEz. Prólogo, cit., 21 ss.).

105 En efecto, ambas expresiones serían una traducción aproximada al castellano de las originales en quechua (sumak kawsay), aimara (sumak kamaña), guaraní (teko kavi) y mapuche (küme mogen), tal como observa J. Estermann. Ecosofía andina: un paradigma alternativo de convivencia cósmica y de Vivir Bien. Revista FAIA - Filosofía Afro-Indo-Americana. Vol. II (IX-X), 2013, 9 (consultado el 25/09/2015 en http://dialnet.unirioja.es/ejemplar/366916).

106 He aquí los tres pilares del "nuevo constitucionalismo andino", que según Melo, M. De Montecristi a Cochabamba. Los derechos de la madre tierra en debate. En EsPinosa GallegosAnda, C. y Pérez Fernández, C., eds., Los derechos de la Naturaleza y la naturaleza de sus derechos, cit., 125, estarían representados por: i) los "derechos de la Natuleza", ii) el "principio etico-moral del 'Buen Vivir'/"Vivir Bien"”, y iii) la "plurinacionalidad", entendida en el sentido de "interculturalidad" (ver CEcu/2008, arts. 1, 2, 16[1], 27, etc. y CBol/2009, arts. 1, 3, 9[2], 17 , etc.). 
profunda de la sociedad con base en las ideas fuerza de la interculturalidad y de la descolonización ${ }^{107}$.

Según este paradigma no puede haber crecimiento y mejoramiento para la humanidad (presente y futura) cuando ello se alcanza en detrimento de los demás seres vivos (de ahí que el reconocimiento de los derechos humanos deba ser completado con los de la naturaleza) y, en consecuencia, el desarrollo económico no puede estar guiado únicamente por la producción y acumulación de bienes o de dinero (al estilo del American Way of Life) sino también por el reciclaje de los materiales usados en los sistemas de producción y, sobre todo, por la distribución o redistribución justa de los bienes existentes y por el consumo sostenible ${ }^{108}$; teniendo todo ello como meta final el equilibrio ecológico y social ${ }^{109}$. Desde esta perspectiva el ideal amerindio del "buen vivir"/"vivir bien" (que no debe confundirse con la "buena vida" fomentada por las ideologías neoliberales) constituye un modelo alternativo de desarrollo al sistema capitalista (de tipo "desarrollista" y "consumista") que tendría que orientar tanto la acción del Estado (principalmente respecto a la planificación del régimen económico ${ }^{110}$ como las relaciones de los hombres entre sí (incluidas las transgeneracionales), con los demás seres vivos e, incluso, las de cada uno consigo mismo ${ }^{111}$.

La Ley marco boliviana de la Madre Tierra y de Desarrollo Integral para Vivir Bien 300 (15 de octubre de 2012) ${ }^{112}$ define este principio como:

107 Ver, en este sentido, Medici, A. Teoría constitucional y giro decolonial: narrativas y simbolismo de la Constitución. Reflexiones a propósito de la experiencia de Bolivia y Ecuador. Gaceta constitucional. Vol. 48. Lima, 2011, pp. 339 ss.

108 Sobre este particular ver, entre otros, Spínola, A. L. S. Consumo sustentável: o alto custo ambiental dos produtos que consuminos. Revista de Direito ambiental. Vol. 24. São Paulo, 2001, 209 ss. En esta misma línea cabe mencionar el nuevo Código Civil y Comercial argentino de 2014, que en materia de "contratos de consumo" dispone que "[1] as normas que regulan las relaciones de consumo deben ser aplicadas e interpretadas conforme con el principio de protección del consumidor y el de acceso al consumo sustentable" (art. 1094).

109 En sentido similar se expresa también la Carta de la Tierra de 2000 (La Haya, 29 de junio de 2000), cuyo principio 7 establece la necesidad de "[a]doptar patrones de producción, consumo y reproducción que salvaguarden las capacidades regenerativas de la Tierra, los derechos humanos y el bienestar comunitario". Con más vehemencia aún, el papa FRANCISCO en su Encíclica Laudato si', cit., pár. 194, 176, observa que "[p]ara que surjan nuevos modelos de progreso, necesitamos 'cambiar el modelo de desarrollo global', lo cual implica reflexionar responsablemente 'sobre el sentido de la economía y su finalidad, para corregir sus disfunciones y distorsiones"”.

110 Vid, v.gr., el Título vi "Régimen de desarrollo" (arts. 275, 277, 278, 283, 290 y 319) y, más precisamente, el Título VII "Régimen del Buen Vivir" (arts. 430-415) de la CEcu/2008, y la Cuarta Parte "Estructura y organización económica del Estado" (arts. 306 y 313 ) de la CBol/2009.

111 Ver, una vez más, Estermann, J. Crisis civilizatoria y Vivir Bien. Una crítica fiolosófica del modelo capitalista desde el allin kawsay/suma qamaña andino. Polis. Revista Latinoamericana. Vol. 11 (33). Santiago de Chile, 2012, 6 ss. (consultado el 25/09/2015 en http://polis. revues.org/8396).

112 Esta ley tiene por objeto “... establecer la visión y los fundamentos del desarrollo integral en armonía y equilibrio con la Madre Tierra para Vivir Bien, garantizando la continui- 
... el horizonte civilizatorio y cultural alternativo al capitalismo y a la modernidad que nace en las cosmovisiones de las naciones y pueblos indígena originario campesinos, y las comunidades interculturales y afrobolivianas, y es concebido en el contexto de la interculturalidad. Se alcanza de forma colectiva, complementaria y solidaria integrando en su realización práctica, entre otras dimensiones, las sociales, las culturales, las políticas, las económicas, las ecológicas, y las afectivas, para permitir el encuentro armonioso entre el conjunto de seres, componentes y recursos de la Madre Tierra. Significa vivir en complementariedad, en armonía y equilibrio con la Madre Tierra y las sociedades, en equidad y solidaridad y eliminando las desigualdades y los mecanismos de dominación... (art. 5[2]).

Sin embargo, es necesario aclarar que la adopción de una concepción más "biocéntrica" (o "ecocéntrica") del cosmos y, por consecuencia, del modelo alternativo de desarrollo del "buen vivir"/"vivir bien" no significa que el hombre no puede utilizar la naturaleza y sus recursos ni emplear para ello la técnica, sino que para hacerlo se exije que los procesos productivos sean llevados a cabo en armonía con la "Naturaleza/Pacha Mama/Madre Tierra" y no a costa de su destrucción o depredación ${ }^{113}$, actuando con la responsabilidad del huésped y custodio de una "casa común" ${ }^{114}$. Baste citar a este respecto lo dispuesto por la Carta Constitucional ecuatoriana de 2008 como cierre del Capítulo vir dedicado a los "Derechos de la Naturaleza", donde se afirma que "[1]as personas, comunidades, pueblos y nacionalidades tendrán derecho a beneficiarse del ambiente y de las riquezas naturales que les permitan el buen vivir..." (art. 74) ${ }^{115}$. En el mismo sentido se expresa también la Ley Fundamental boliviana de 2009 cuando dispone que "[1]a agricultura,

dad de la capacidad de regeneración de los componentes y sistemas de vida de la Madre Tierra, recuperando y fortaleciendo los saberes locales y conocimientos ancestrales, en el marco de la complementariedad de derechos, obligaciones y deberes; así como los objetivos del desarrollo integral como medio para lograr el Vivir Bien, las bases para la planificación, gestión pública e inversiones y el marco institucional estratégico para su implementación" (art. 1).

113 Como señalan, entre otros, Gudynas, E. El mandato ecológico: Derechos de la Naturaleza y políticas ambientales en la nueva Constitución. Quito, 2009, 80; ZAFFARONI, E. R. La Pachamama y el humano, cit., 134 s.; Aguilera Bravo, M. y Cóndor Salazar, M. La iniciativa Yasuní-ITT como materialización de los Derechos de la Naturaleza. En Espinosa GaLLEGOs-AndA, C. y Pérez Fernández, C., eds., Los Derechos de la Naturaleza y la naturaleza de sus derechos, cit., 214, y Aparicio Wilhelmi, M. Nuevo constitucionalismo, derechos y medio ambiente en las Constituciones de Ecuador y Bolivia, cit., p. 9.

114 En efecto, tal como explica Estermann. Crisis civilizatoria y Vivir Bien, cit., p. 8, "[1]a economía, y, por tanto, el desarrollo económico, es para la pachasofía andina el manejo prudente y cuidadoso de la Casa Común (wasi; uta) que es el universo (Pacha)". La identificación de la Tierra con la "casa común" de todos los seres vivos y la condición de custodio de la misma reconocida al hombre son destacadas también por la reciente Encíclica del papa FRANCISCO Laudato si' subtitulada "sobre el cuidado de la casa común". Para referir a esta misma idea la Carta de la Tierra de 2000 ha empleado, en cambio, la expresión sinonímica "nuestro hogar" (ver Preámbulo).

115 Este mismo artículo precisa además que si bien "[1]os servicios ambientales no serán 
la ganadería, así como las actividades de caza y pesca que no involucren especies animales protegidas, son actividades que se rigen por lo establecido en la cuarta parte de esta Constitución referida a la estructura y organización económica del Estado" (art. 311[ı.2]), y cuando permite "[1]a industrialización de los recursos naturales para superar la dependencia de la exportación de materias primas y lograr una economía de base productiva, en el marco del desarrollo sostenible, en armonía con la naturaleza" (art. 311[г.3]) ${ }^{116}$.

Por último corresponde destacar que este modelo de desarrollo alternativo, inspirado por la visión holística del "buen vivir"/"vivir bien", coincide también en términos generales con el propuesto por la Alianza Bolivariana para América (ALBA) ${ }^{117}$, alianza creada en La Habana el 14 de diciembre de 2004 y concebida inicialmente como una alternativa al Área de Libre Comercio de las Américas (ALCA $)^{118}$, cuya finalidad consiste en: i) promover la transferencia de bienes y capitales de acuerdo a criterios de solidariedad, reciprocidad y complementariedad; ii) otorgar prioridad a la relaciones internacionales en pie de igualdad, y iii) tratar de sustituir el principio de la competencia entre Estados fundada en el egoísmo individual y nacional (defendido por el sistema capitalista) por el principio de la ayuda y del apoyo mutuo (propuesto por el denominado "socialismo democrático") ${ }^{119}$. En cumplimiento de estos objetivos, los países miembros del ALBA-TCP (junto con los presidentes y representantes de otros países latinoamericanos) reiteraron su crítica al modelo neoliberal de reducir el medio ambiente a una mercancía, esto en el "Manifiesto de las Américas en defensa de la Naturaleza y la diversidad biológica y cultural" (Curitiba, 20 de abril de 2006), destacando una vez más la necesidad de "pasar de una Sociedad de Producción Industrial, consumista e individualista, que sacrifica los ecosistemas y penaliza a las personas, destruyendo la socio-biodiversidad, a una Sociedad de Sustentación de Toda la Vida, que se encamine por una vía socialmente justa y ecológicamente sostenible para

susceptibles de apropiación", la producción, prestación, uso y aprovechamiento de los mismos podrá ser llevada a cabo por los particulares en la forma regulada por el Estado (art. $74^{i . f}$ ).

116 Además pueden verse, con esta misma orientación, los artículos 316[6] y 319.I. Por su parte, la ya citada Ley 300 de 2012 aclara en su artículo 5[4], al definir los componentes de la Madre Tierra, que los mismos "... bajo condiciones de desarrollo sustentable pueden ser usados o aprovechados por los seres humanos, en tanto recursos naturales, como lo establece la Constitución Política del Estado".

117 Sobre la cual remitimos, en general, a Briseño Ruiz, J. El ALBA: una discusión de su modelo, sus resultados y sus perspectivas. Anuario de la Integración Regional de América Latina y el Caribe. Vol. 10. Buenos Aires, 2014, 151 ss.

118 La denominación de esta organización se amplió (ALBA-TCP) para incluir el Tratado de Comercio de los Pueblos (TCP), firmado en La Habana el 29 de abril de 2006, como una alternativa a los acuerdos de libre comercio impulsados en la región por Estados Unidos (sobre los cuales remitimos, en general, a Tole, J. J. Los TLC de Estados Unidos con países latinoamericanos: un modelo de integración económica "superficial" para el Continente americano. Revista Derecho del Estado. Vol. 30. Bogotá, 2013, 251 ss.).

119 Como observa también Estermann. Ecosofía andina, cit., p. 12. 
vivir, cuide de la comunidad de vida y proteja las bases físico-químicas y ecológicas que sustentan todos los procesos vitales, incluidos los humanos" ${ }^{120}$.

\section{CONCLUSIONES}

Con base en lo hasta aquí analizado puede concluirse que:

a) El especial interés demostrado por el derecho (tanto nacional como supranacional) de América Latina respecto a la denominada "cuestión ecológica" constituye otro de los elementos de unidad y, a la vez, de resistencia del sistema jurídico latinoamericano, cuya base socio-cultural ha sido identificada en el denominado "bloque romano-indígena", según el cual el hombre no es tomado en consideración como un "individuo aislado" (tal como sucede en otras experiencias jurídicas, como la del common law) sino en estrecha relación con la "comunidad" y su "entorno" (integrado por seres humanos y por seres no humanos).

b) Esta particularidad del sistema jurídico latinoamericano reconoce su fuente tanto en la tradición romanística (recibida, primero, a través del "derecho común ibero-americano" desarrollado durante el período colonial y, después, mediante su transfusión en las codificaciones que se dieron las repúblicas iberoamericanas luego de su independencia) como también en el "mestizaje" de dicha tradición con las cosmovisiones de los pueblos originarios de América Latina (las cuales fueron generalmente descuidadas por las codificaciones decimonónicas pero revalorizadas principalmente por el "nuevo constitucionalismo latinoamericano"), caracterizadas ambas vertientes del derecho latinoamericano por una profunda "socialidad" en todo el arco de sus respectivos desarrollos históricos.

c) El actual modelo ecológico de América Latina tendría sus antecedentes en la preocupación demostrada por el "constitucionalismo social" latinoamericano en reglamentar el aprovechamiento de los recursos naturales de la región, a través de su "demanialización" y al exigir que la explotación de los mismos se hiciere en forma regular y racional, aun cuando en esta primera regulación de la materia la protección de la naturaleza se encontrara

120 Ver, sobre este particular, Roncal Vattuone, E. X. La naturaleza... un sujeto con derechos. Apuntes para la reflexión. Integra Educativa. Revista de Investigación Educativa del Instituto Internacional de Integración del Convenio Andrés Bello. Vol. 18. La Paz, 2013, 129 ss. En sentido similar se ha expresado también la ya citada Declaración de la segunda Conferencia Mundial de los Pueblos sobre Cambio Climático y Defensa de la Vida (Cochabamba, 12 de octubre de 2015), al exigir "el impulso y transformación de la matriz productiva en lo local, nacional e internacional, a prácticas soberanas y armónicas con la naturaleza y la vida (agricultura familiar, agro ecología entre otros)" (par. 1.6) y la necesidad de "[c]onstruir e impulsar el modelo económico productivo armónico igualitario para Vivir Bien con el horizonte hacia el ecososialismo basado en una relación armómica entre el hombre y la naturaleza que garantice el uso y aprovechamiento racional óptimo sostenible y sustentable de los recursos respetando los procesos y ciclos de la naturaleza" (par. 3.5). 
motivada no tanto en consideración al respeto del medio ambiente sino casi exclusivamente en criterios económicos.

d) La preocupación del derecho latinoamericano por la "cuestión ambiental" cobró impulso a causa del desarrollo del "derecho ambiental internacional", especialmente con motivo de las conferencias de las Naciones Unidas de Estocolmo (1972) y Río de Janeiro (1992), y se intensificó con el advenimiento del denominado "nuevo constitucionalismo latinoamericano" y el desenvolvimiento de un verdadero "constitucionalismo ambiental" que reconoció ampliamente el derecho humano a un medio ambiente adecuado y sostenible, con carácter transversal, imponiendo tanto al Estado como a la sociedad el deber de respetarlo, y garantizando su efectividad a través de la introducción de mecanismos procesales adecuados a su naturaleza (acciones populares, de amparo, etc.) y/o encomendando su defensa a ciertos órganos estatales encargados de tutelar los intereses de la colectividad (Ministerio Público, Defensor del Pueblo, etc.).

e) Empero la protección -más o menos articulada- del derecho humano al mendio ambiente prevista por la casi totalidad de las constituciones latinoamericanas no ha logrado evitar del todo la depredación de la naturaleza, en atención a que el mismo sigue respondiendo a una concepción marcadamente "antropocéntrica" y "economicista/utilitarista" de inspiración cartesiana; de ahí que consideramos digno de elogio que el denominado "nuevo constitucionalismo andino", retomando principalmente la cosmovisión de los pueblos originarios de América Latina (así como también la noción del ius naturale heredada de la tradición romano-ibérica), haya propuesto reconocer directamente a la "Naturaleza/Pacha Mama/Madre Tierra" el carácter de sujeto de derecho (pasándose, de esta manera, del "ambientalismo" al "ecologismo") y haya completado este cambio de paradigma protectivo del medio ambiente con la adopción de un modelo de desarrollo alternativo al capitalismo fundado, no ya en el "desarrollismo" y "consumismo" de tipo neoliberal, sino en el principio ético-moral amerindio del "buen vivir"/"vivir bien", cuya meta final consiste en alcanzar un equilibrio ecológico y social.

\section{BIBLIOGRAFÍA}

Acuña Solórzano, G. M. Los interdictos populares como instrumento de tutela a las res in usu publico en el Derecho romano y su influencia en las codificaciones latinoamericanas. Con atención a la tutela ambiental. Roma e America. Diritto romano comune. Vol. 25. Modena-Bogotá, 2008, 53-80. Disponible en: www.romaeamerica.it

Aguilera Bravo, M. y Cóndor Salazar, M. La iniciativa Yasuní-ItT como materialización de los derechos de la naturaleza. En C. Espinosa Gallegos-Anda y C. Pérez Fernández, eds., Los derechos de la naturaleza y la naturaleza de sus derechos. Quito, 2011, 209-242.

Amaya Navas, O. D. El medio ambiente y los estados de excepción. Revista Derecho del Estado. Vol. 1. Bogotá, 1997, 77-79. 
Aparicio Wilhelmi, M. Nuevo constitucionalismo, derechos y medio ambiente en las Constituciones de Ecuador y Bolivia. Revista General de Derecho Público Comparado. Vol. 9. Madrid, julio 2011, 1-24.

Ávila Santamaría, R. El derecho de la naturaleza: fundamentos. En A. Acosta y E. Martínez, comps., La naturaleza con derechos. De la filosofía a la política. Quito, 2011, 173-238.

Benjamin, A. H. V. A natureza no direito brasileiro: coisa, sujeito ou nada disso. Nomos. Revista do Programa de Pós-graduação em Direito da UFC [Universidade Federal do Ceará]. Vol. 31 (1). Fortaleza, 2011, 79-96.

Benjamin, A. H. V. A proteção do meio ambiente nos países menos desenvolvidos: o caso da América Latina. Revista de Direito Ambiental. Vol. 0, São Paulo, 1995, 83-105.

Benjamin, A. H. V. Responsabilidade civil pelo dano ambiental. Revista de Direito ambiental. Vol. 9. São Paulo, 1998, 5-52.

Bentham, J. An Introduction to the Principles of Morals and Legislation. London, 1780.

Boff, L. Do iceberg ao Arca de Noé. Petrópolis, 2002.

Bolinaga, M. B. Bolivar conservacionista. Caracas, 1982.

Brañes, R. El constitucionalismo ambiental latinoamericano. En G. Cordini y A. PostiGLIOne, eds., Ambiente e cultura. Patrimonio comune dell'Umanità. Atti della VII ${ }^{a}$ Conferenza Internazionale ICEF (Paestum, 6-10 giugno 1997). Napoli, 1999, 129 ss.

BRAÑES, R. Informe sobre el desarrollo del derecho ambiental latinoamericano. Su aplicación después de diez años de la Conferencia de las Naciones Unidas sobre el Medio Ambiente y el Desarrollo. Programa de las Naciones Unidas para el Medio Ambiente (PNuma). México, D. F., 2001.

Briseño Ruiz, J. El Alba: una discusión de su modelo, sus resultados y sus perspectivas. Anuario de la Integración Regional de América Latina y el Caribe. Vol. 10. Buenos Aires, 2014, 151-178.

Cabrera Medaglia, J. A. El impacto de las Declaraciones de Río y Estocolmo sobre la legislación y las políticas ambientales en América Latina. Revista de Ciencias Jurídicas. Universidad de Costa Rica. Vol. 100. San José de Costa Rica, 2003, 301-331.

Cafferata, N. A. Instituciones de derecho ambiental latinoamericano. Revista de Derecho Público. Vol. 2009-2 (Derecho ambiental). Santa Fe-Buenos Aires, 9-45.

Cançado Trindade, A. A. Direitos Humanos e meio-ambiente. Paralelo dos sistemas de proteção internacional. Porto Alegre, 1993.

CAPRA, F. The Web of Life: A New Scientific Understanding of Living Systems. New York, 1997.

Castellucci, I. Sistema jurídico latinoamericano. Una verifica. Torino, 2011.

Catalano, P. Choque de sistemas jurídicos en la perspectiva romana latinoamericanista. A propósito del "bloque romano-indígena": de Xalapa 1974 a Morelia 2006. En J. 
L. Cuevas Gayosso, comp. Estudios en homenaje a Mercedes Gayosso y Navarrete. Xalapa, 2009, pp. 23-62.

Catalano, P. Diritto e persone. Torino, 1990.

Cavalieri, P. y Singer P., eds. The Great Ape Project: Equality Beyond Humanity. New York, 1993

Cullinan, C. Wild Law. A Manifesto for Earth Justice. Cape Tawn, 2002.

Estermann, J. Crisis civilizatoria y Vivir Bien. Una crítica fiolosófica del modelo capitalista desde el allin kawsay/suma qamaña andino. Polis. Revista Latinoamericana. Vol. 11 (33). Santiago de Chile, 2012 (consultado el 25/09/2015 en http://polis.revues.org/8396).

ESTERMANn, J. Ecosofía andina: un paradigma alternativo de convivencia cósmica y de Vivir Bien. Revista FAIA - Filosofía Afro-Indo-Americana. Vol. II (IX-X), 2013 (consultado el 25/09/2015 en http://dialnet.unirioja.es/ejemplar/366916).

Estermann, J. Filosofía andina. Estudio intercultural de la sabiduría autóctona andina. Quito, 1998.

Gargarella, R. y Courtis, Chr. El nuevo constitucionalismo latinoamericano: promesas e interrogantes. CEPAL - Serie Políticas Sociales. Vol. 153. Santiago de Chile, 2009.

GonzÁLez, M. del R. Del Señorío del Rey a la propiedad originaria de la Nación. Anuario Mexicano de Historia del Derecho. Vol. 5. México, D. F., 1993, pp. 129-150.

Gudynas, E. El mandato ecológico: Derechos de la Naturaleza y políticas ambientales en la nueva Constitución. Quito, 2009.

Gudynas, E. La ecología política del giro biocéntrico en la nueva Constitución de Ecuador. Revista de Estudios Sociales. Vol. 32. Bogotá, abril de 2009, 34-46.

Gudynas, E. Los Derechos de la Naturaleza y la construcción de una justicia ambiental y ecológica en Ecuador. En C. Espinosa Gallegos-Anda y C. Pérez Fernández, eds., Los derechos de la Naturaleza y la naturaleza de sus derechos. Quito, 2011, 95-122.

Izaguirre Sarkís, C. Introducción al Derecho ambiental. En G. Aguilar y A. Iza, eds. y dirs. Manual de Derecho ambiental en Centroamérica. San José de Costa Rica, 2005, 23-66.

Limonta Esteves Grizzi, A. L. Direito ambiental aplicado aos contratos. São Paulo, 2008.

Llasag Fernández, R. Derechos de la Naturaleza: una mirada desde la filosofía indígena y la Constitución. En C. Espinosa Gallegos-Anda y C. Pérez Fernández, eds., Los derechos de la Naturaleza y la naturaleza de sus derechos. Quito, 2011, 75-92.

Lobrano, G. Uso dell'acqua e diritto nel Mediterraneo. Uno schema di interpretazione storico sistematica e de iure condendo.Diritto@Storia.Rivista internazionale di scienze giuridiche e tradizione romana. Sassari, 2004 (consultado el 25/09/2015 en http:// www.dirittoestoria.it/3/TradizioneRomana/Lobrano-Acqua-diritto-Mediterraneo.htm).

Lovelock, J. E. Gaia. A New Look at Life on Earth. Oxford, 1979. 
Melo, M. De Montecristi a Cochabamba. Los derechos de la madre tierra en debate. En C. Espinosa Gallegos-Anda y C. Pérez Fernández, eds., Los derechos de la Naturaleza y la naturaleza de sus derechos. Quito, 2011, 123-138.

Maliré, É. y de Ávila Aguiar Coimbra, J. Antropocentrismo x ecocentrismo na Ciência jurídica. Revista de Direito ambiental. Vol. 36. São Paulo, 2004, 9-41.

Marcelli, F. La tutela dell'ambiente e la partecipazione democratica come elementi di una nuova identità latino-americana emergente. En G. CATALDI y A.PAPA, coords. Ambiente, diritti e identità culturale. Napoli, 2006, 251 ss.

Martínez, E. Prólogo. En A. Acosta y E. Martínez, comps. La naturaleza con derechos. De la filosofía a la política. Quito, 2011, 7-23.

Meadows, D. H., Randers, J. y Behrens iII, W. W. The Limits to Growth. New York, 1972.

Medici, A. Teoría constitucional y giro decolonial: narrativas y simbolismo de la Constitución. Reflexiones a propósito de la experiencia de Bolivia y Ecuador. Gaceta constitucional. Vol. 48. Lima, 2011, 329-348.

MeIER, H. El derecho ambiental y el nuevo milenio. Caracas, 2003.

Moreira, A. C. La protección ambiental en los procesos de integración. Aportes para cubrir un déficit del Mercosur. Anuario Mexicano de Derecho Internacional. Décimo Aniversario. México, D. F., 2012, 211-232.

Nonna, S. C. Derecho ambiental en América Latina. Buenos Aires, 1996.

Oliveira Mazzuoli, V. De. A proteção internacional dos Direitos Humanos e o Direito Internacional do medio ambiente, Revista de Direito ambiental. Vol. 34. São Paulo, 2004, 97-123.

OnIDA, P. P. Il problema della personalità degli animali: il caso dell'orango Sandra. Roma e America. Diritto romano comune. Vol. 36, Modena-Bogotá, 2015. Disponible en: www.romaeamerica.it

ONIDA, P. P. Studi sulla condizione degli animali non umani nel sistema giuridico romano. Torino, 2012.

Ost, F. La nature hors la loi. L'écologie à l'épreuve du droit. Paris, 1995.

PAPA Francisco. Laudato si'. Carta Encíclica sobre el cuidado de la casa común. Città del Vaticano: Libreria Editrice Vaticana, 2015.

Pellegrini Grinover, A. Proyecto de Código Modelo de Procesos Colectivos para Iberoámerica. Roma e America. Diritto romano comune. Vol. 17. Modena-Bogotá, 2004 257-264 (www.romaeamerica.it).

Pérez Royo, J. Influencia del constitucionalismo español en el constitucionalismo iberoamericano. En M. Carbonell, J. Carpizo y D. Zovatto, coords. Tendencias del constitucionalismo en Iberoamérica. México, D. F., 2009, 419-430.

PiCARI, N. Naturaleza y territorio desde la mirada de los pueblos indígenas. En A. Acosta y E. Martínez, comps., Derechos de la Naturaleza. El futuro es ahora. Quito, 2009, 31-37. 
Prieto Méndez, J. M. Derechos de la Naturaleza. Fundamentos, contenido y exigibilidad jurisdiccional. Quito, 2013.

RÁbago Dorbecker, M. Derechos de propiedad: artículo 27 constitucional y artículo 21 convencional. En E. Ferrer Mac-Gregor Poisot, J. L. Caballero Ochoa y Chr. SteiNER, coords. Derechos Humanos en la Constitución. Comentarios de jurisprudencia constitucional e interamericana. Vol. II. México, D. F., 2013, 2299-2335.

Real Ferrer G., ed. Integración económica y medio ambiente en América Latina. Madrid, 2000.

Regan, T. The Case for Animal Rights. Los Angeles, 1983.

Roncal Vattuone, E. X. La naturaleza... un sujeto con derechos. Apuntes para la reflexión. Integra Educativa. Revista de Investigación Educativa del Instituto Internacional de Integración del Convenio Andrés Bello. Vol. 18. La Paz, 2013, 121-136.

Schipani, S. La codificazione del diritto romano comune. Torino, 1999.

Singer, P. Animal Liberation. New York, 1975.

SPínola, A. L. S. Consumo sustentável: o alto custo ambiental dos produtos que consuminos. Revista de Direito ambiental. Vol. 24. São Paulo, 2001, 209-216.

Stone, Chr. Should Trees Have Standing? Toward Legal Rights for Natural Objects, Southern California Law Review. Vol. 45. Los Angeles, 1972, 450-501.

Stutzin, G. Un imperativo ecológico: reconocer los Derechos de la Naturaleza, Ambiente y Desarrollo. Vol. I (1). Santiago de Chile, diciembre 1984, 97-114.

Tole, J. J. Los TLC de Estados Unidos con países latinoamericanos: un modelo de integración económica "superficial" para el Continente americano. Revista Derecho del Estado. Vol. 30. Bogotá, 2013, 251-300.

Trisciuoglio, A. Tutela del Medio Ambiente (Roma, Europa, América Latina). En M. I. Álvarez Ledesma y R. Cippitani, coords. Diccionario analítico de Derechos Humanos e integración jurídica. Roma-Perugia-México, D. F., 2013, 691-699.

Ulate Chacón, E., Rodríguez Brunett, O. A. y Cabrera Medaglia, J. Derecho agrario y desarrollo sostenible. San José de Costa Rica, 2000.

Zaffaroni, E. R. La Pachamama y el humano. En A. Acosta y E. Martínez, comps. La naturaleza con derechos. De la filosofía a la política. Quito, 2011, 25-137. 